\title{
A DISSERTATION IN
}

Nursing

\author{
Presented to the Faculty of the University \\ of Missouri-Kansas City in partial fulfillment \\ of the requirements for the degree

\section{DOCTOR OF PHILOSOPHY}

\author{
by \\ NANCY (NIKI) EISENMANN \\ BSN University of Nebraska Medical Center, 2002 \\ MSN Nebraska Wesleyan University, 2009
}

\author{
Kansas City, Missouri \\ 2018
}


COPYRIGHT PAGE 


\title{
DIFFERENCES BETWEEN LICENSED HEALTHCARE PROFESSIONALS WITH SUBSTANCE USE-RELATED LICENSURE DISCIPLINE
}

\author{
Nancy Nicole Eisenmann, Candidate for the Doctor of Philosophy Degree \\ University of Missouri Kansas City, 2019
}

\begin{abstract}
Substance Use Disorder (SUD) affects thousands of physicians, nurses, pharmacists and other healthcare providers across the country. Healthcare providers who suffer from SUD are different from those in the general population who suffer from SUD, because the healthcare provider must be able to think and act appropriately to perform the duties of their respective jobs. Healthcare providers who misuse substances present not only a risk to their own health, but may also threaten the health, safety, and welfare of the patients in their care. The potential for patient harm is the cause for licensure discipline, as licensing jurisdictions seek to protect their healthcare consumers. Licensure discipline, however, may deter the provider from seeking appropriate treatment, causing them to continue practicing, while trying to avoid detection. This places patients at risk for harm. The purpose of this secondary data analysis is to compare the licensure discipline of nurses, physicians, and pharmacists with substance use disorder. Chi-square tests are used to compare disciplinary action from each profession reported to the National Practitioner Data Bank from 2007-2017 in 24 states. Eight different disciplinary outcomes are
\end{abstract}


compared among the three professions based on eight grounds for discipline related to substance use disorder.

Keywords: Licensure discipline, healthcare professionals, substance use disorder. 


\section{APPROVAL PAGE}

The faculty listed below, appointed by the Dean of the School of Nursing and Health Studies, have examined a dissertation titled" Differences Between Licensed Healthcare Professionals with Substance Use-Related Licensure Discipline,” presented by Nancy Eisenmann, candidate for the Doctor of Philosophy degree, and certify that in their opinion it is worthy of acceptance.

$\underline{\text { Supervisory Committee }}$

Eduardo Abreu, PhD, MD, Committee Chair

Department of Nursing

Anita Skarbek, PhD, RN

Department of Nursing

Carol Schmer, PhD, RN

Department of Nursing

Singbeck Ye, PhD

Department of Nursing

Dave Miers, PhD, LIPC

Department of Nursing

Mental Health Services Administration

Bryan Medical Center 


\section{CONTENTS}

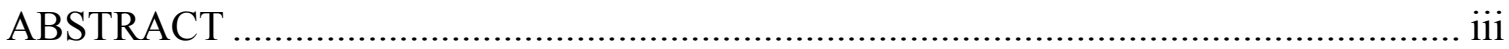

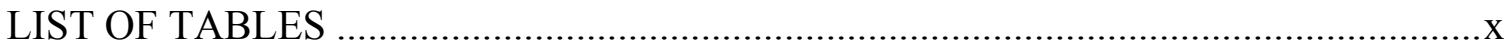

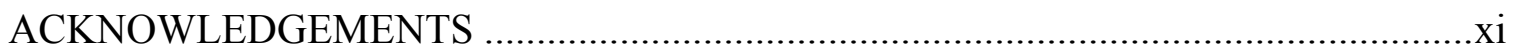

Chapter

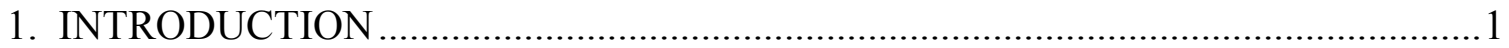

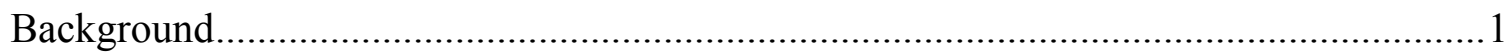

History of the problem of SUD in healthcare professionals............................................

Incidence

Risk factors unique to health care professionals .........................................................

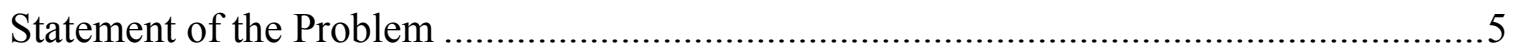

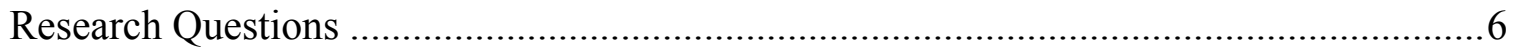

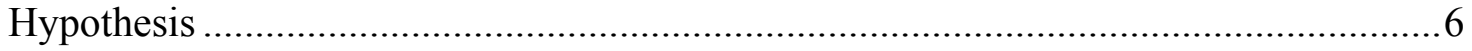

Operational Definitions ........................................................................................

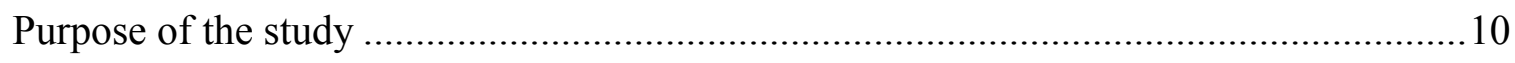

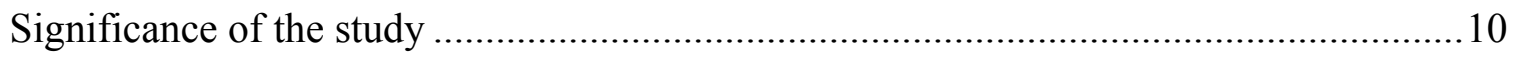

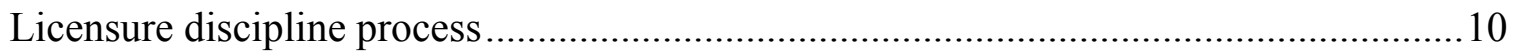

Punitive Versus Non-Punitive Discipline ........................................................................ 14

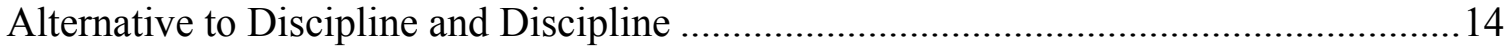

Chapter

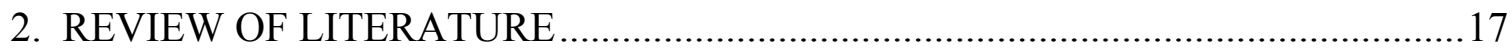

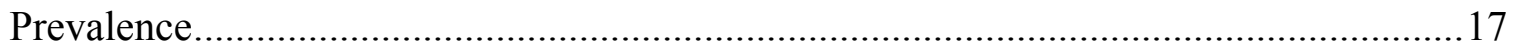




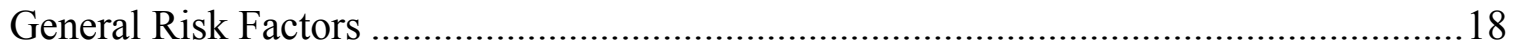

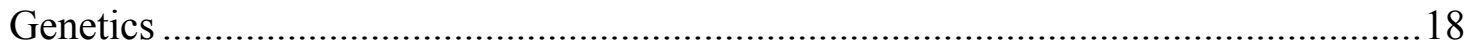

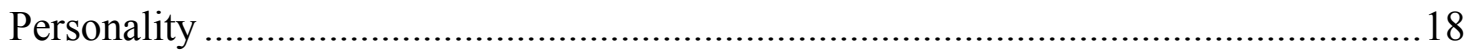

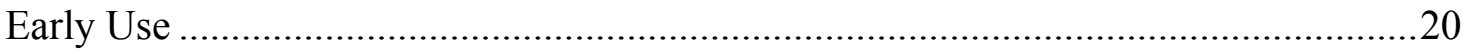

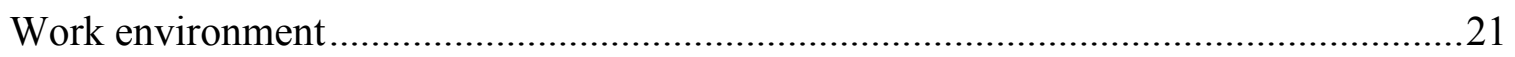

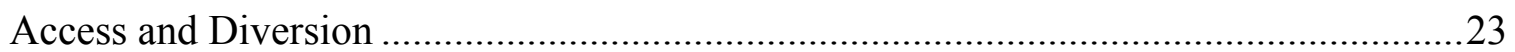

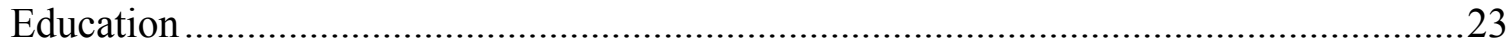

Summary

Chapter

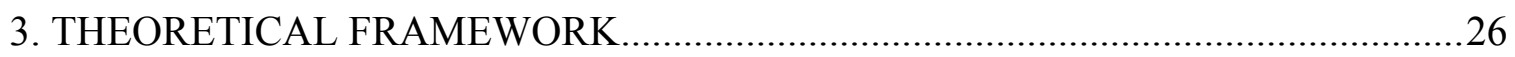

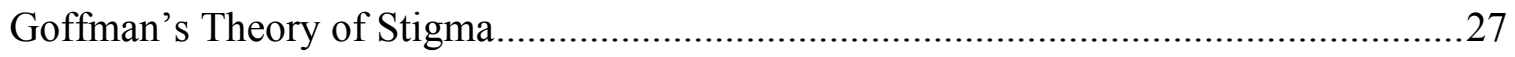

Disease Related Stigma: Substance Use Disorder............................................................30

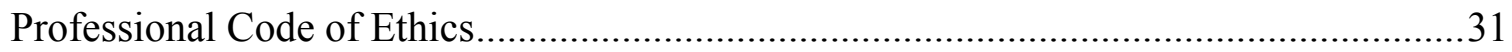

Stigma and Discipline

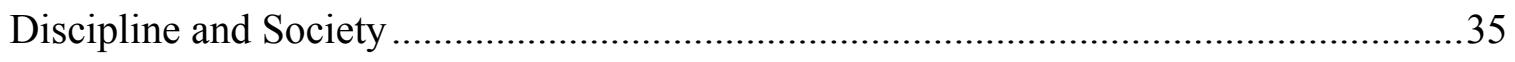

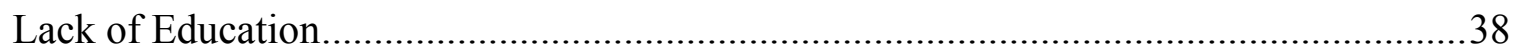

Chapter

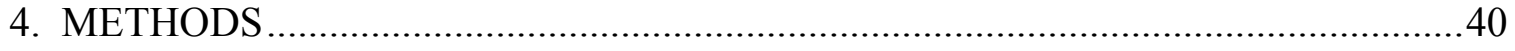

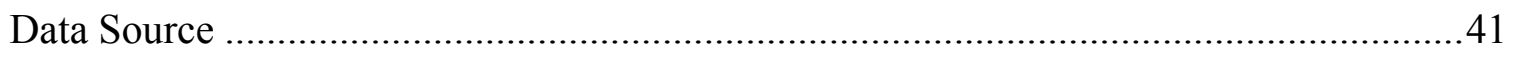

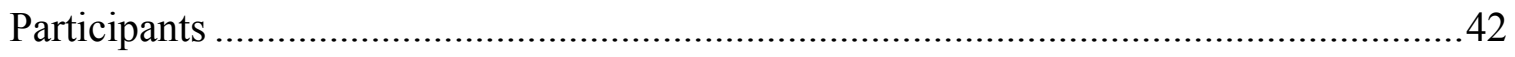

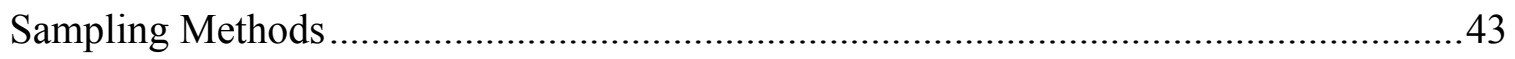

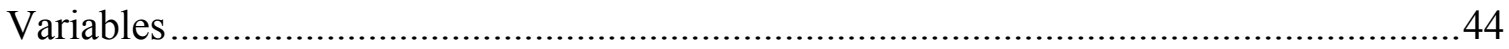




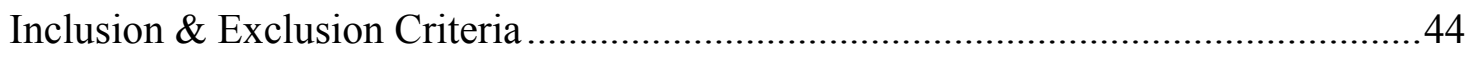

Independent Variable: Type of Licensure ................................................................ 44

Dependent Variable: Disciplinary Action (Adverse Outcome)....................................45

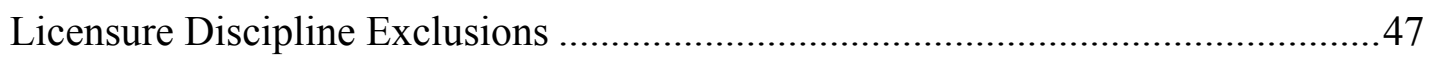

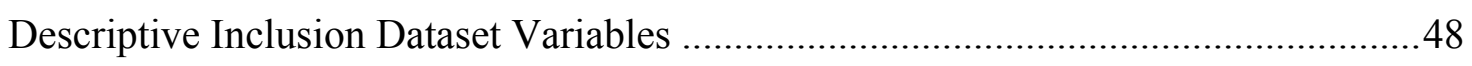

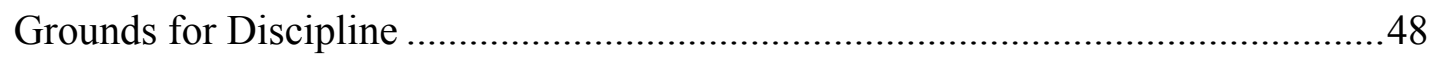

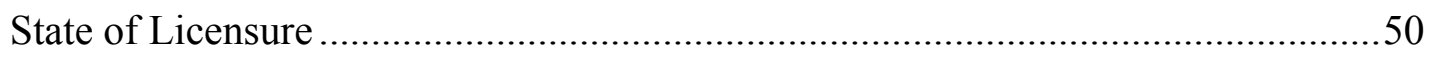

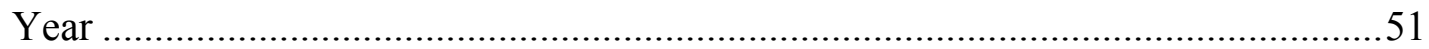

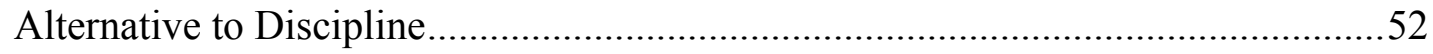

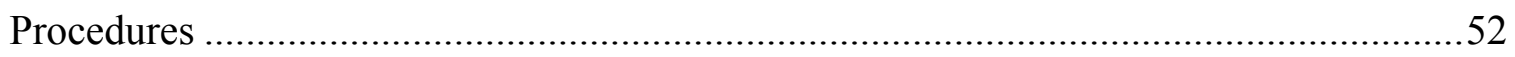

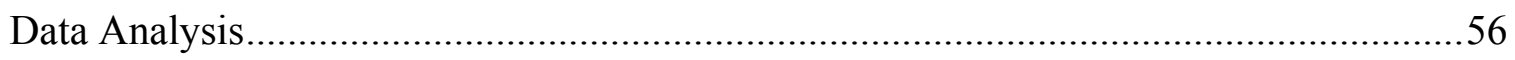

Chapter

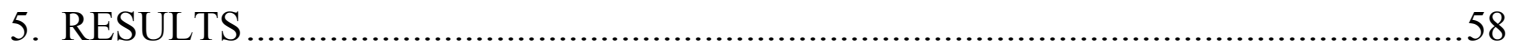

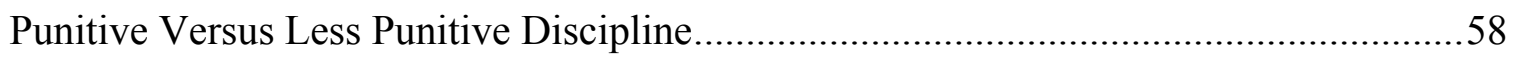

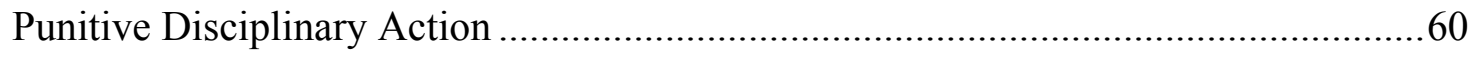

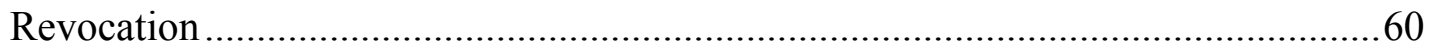

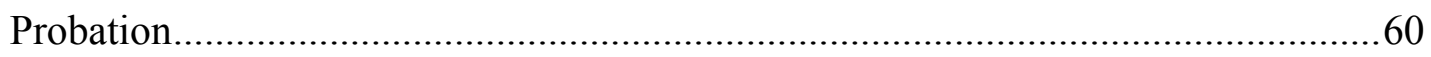

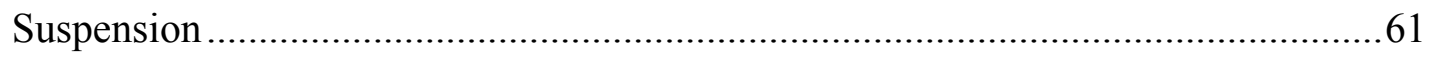

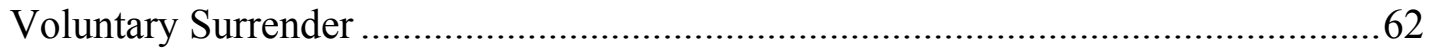

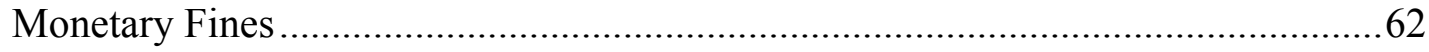

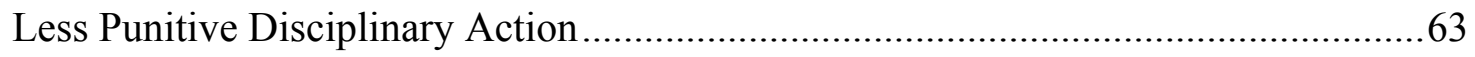

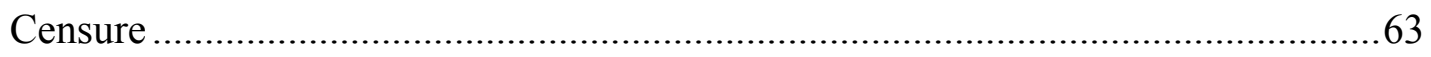

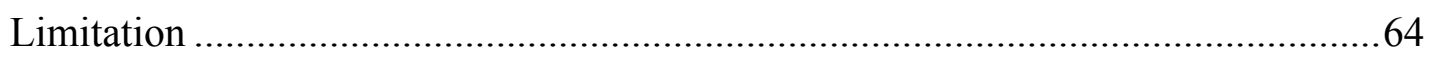

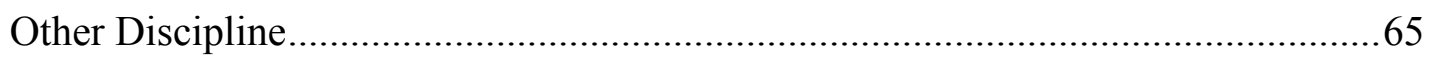

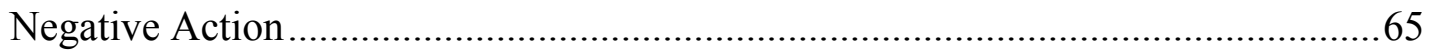




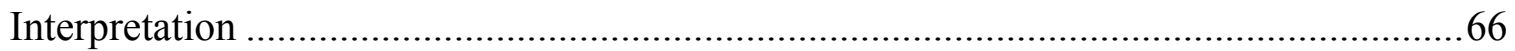

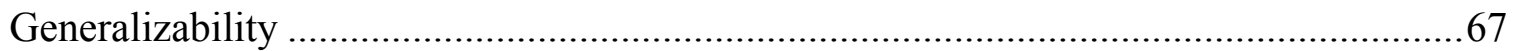

Chapter

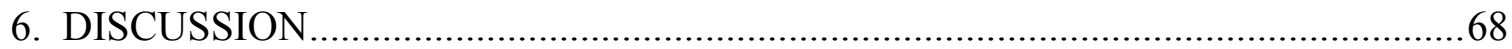

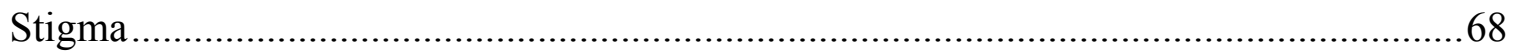

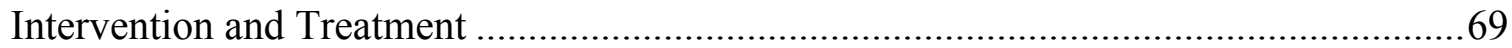

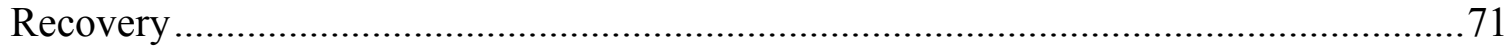

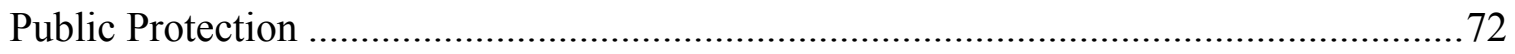

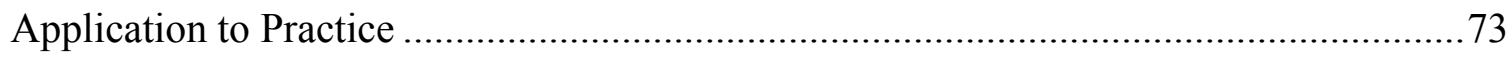

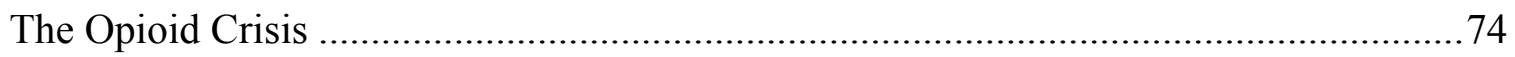

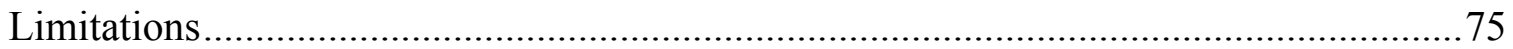

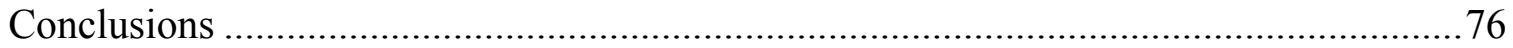

Appendix

A: National Practitioner Data Bank Public Use File .................................................. 78

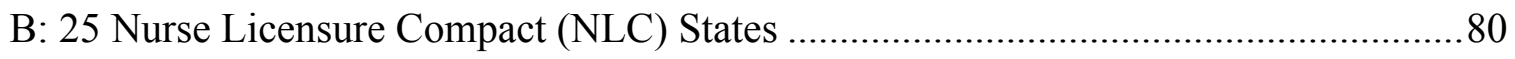

C: From the Nurse Licensure Compact Statutes ...................................................... 81

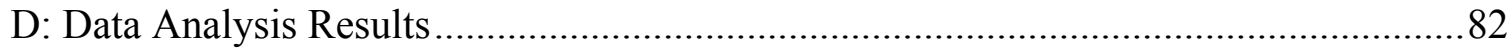

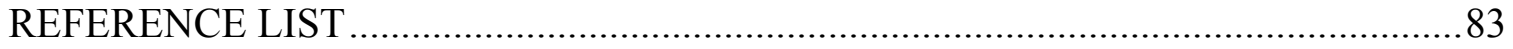

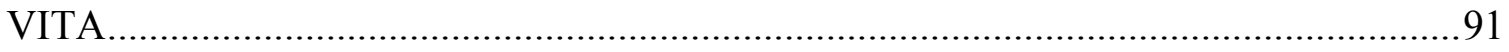




\section{TABLES}

Table

Page

4.1 Licensure Types in Dataset.....................................46

4.2 Disciplinary Action Dataset.....................................49

4.3 Grounds for Disciplinary Action in Dataset.........................51

5.1 Chi-Square Analysis of Revocation..............................61

5.2 Chi-Square Analysis of Probation.................................62

5.3 Chi-Square Analysis of Suspension..............................63

5.4 Chi-Square Analysis of Voluntary Surrender.........................64

5.5 Chi-Square Analysis of Monetary Fines............................64

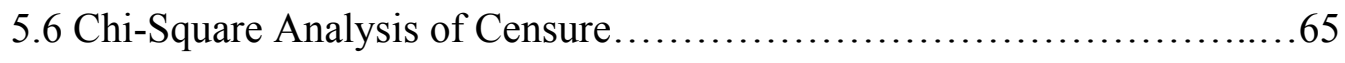

5.7 Chi-Square Analysis of Limitation...............................65

5.8 Chi-Square Analysis of Other Discipline..........................66

5.9 Chi-Square Analysis of Negative Action Discipline....................67 


\section{ACKNOWLEDGEMENTS}

The passion for impaired healthcare providers came from personal experience with an impaired dental provider who caused me significant pain and harm. The experience was the beginning of the desire to make a positive impact on the practice environment for providers suffering from substance use disorder. This study is only the beginning. Thank you to Teresa Roddy, who despite so much push back and bullying from the State of Nebraska in the beginning stages of this doctorate encouraged me to press forward. I love being a nurse. This profession gives me the ability to advocate for those who need a voice. I will continue to advocate and speak on behalf of those who have or are recovering from substance use disorders especially those in my profession. .

I would also like to acknowledge Jonas Philanthropies for their support in being selected as a Jonas Nurse Leader Scholar. I am extremely grateful for the support and opportunities this organization provided and will continue to work very hard to promote the health and welfare of the nursing community through my research.

I would like to acknowledge Dr. Eduardo Abreu for taking me on at the end of this process. It was not an easy task to chair a non-existent dissertation committee in a new area of study. I am more grateful for your help in finishing this PhD than you know. I would like to acknowledge all my committee members. Your time and expertise are so appreciated! 


\section{DEDICATION}

$\mathrm{A} \mathrm{PhD}$ is not earned without a lot of help. This doctorate is no exception. To my parents, George and Sharon Schamber for your patience and love in raising a strong willed girl who is relentless and fearless enough to take on the challenge of a terminal degree. Without you telling me I could do anything I set my mind to and encouraging me to chase every silly little goal and dream I may not be here. To my sweet daughters Calla and Izzy, I know this has not been an easy process. You were little when this started and endured much of this process with me as you grew at times even thinking I "enjoyed painful things". You girls were the ones I persevered for. I hope you learned how important education is and how hard work pays off. To my amazing husband Scott, thank you for loving me through a doctorate for five years and for your endless support, sacrifice, and encouragement. There were times, especially early on, it seemed you were the only one cheering me on. You knew the goal and pushed me more than everyone to get there. This dissertation is also dedicated in part to the many healthcare providers and patients who have been affected by substance use disorder. 


\section{CHAPTER 1}

\section{INTRODUCTION}

\section{Background}

Substance Use Disorders (SUD) are a significant problem in the United States, affecting approximately 2.5 million adults, or $7.5 \%$ of the population (Substance Abuse and Mental Health Administration [SAMSHA], 2014). Healthcare providers are not immune to the problem. The prevalence of the problem of SUD in nurses, physicians, and pharmacists is thought to be similar to that of the general population. Although each type of licensed healthcare provider has a unique role in the delivery of health services to patients, the services provided require the application of knowledge, and skilled precision with interventions. Nurses, physicians, and pharmacists are all required to function at a high level to perform their respective professional duties safely and effectively. Healthcare providers impaired by substances such as drugs or alcohol, present danger to the patients entrusted to their care. The dangers posed to patients range from minor medical errors and poor pain control to exposure to communicable diseases and death (Shaefer \& Perz, 2014). If the rates of SUD in the healthcare professions follow the general population, this would equate to 194,038 impaired nurses, 75,000 impaired physicians, and 22,193 impaired pharmacists in the United States every year (Bureau of Labor Statistics, 2016; SAMSHA, 2014).

\section{History of SUD in the Healthcare Professions}

The rates of SUD nationwide continue to rise in epidemic proportions across healthcare disciplines (Lipari \& Van Horn, 2017). Contributing to this issue are significant increases in opioid use disorders as well as an intense risk in opioid related 
overdose deaths (Lipari \& Van Horn, 2017). Healthcare professionals are not immune to SUD and have ready access to Schedule II narcotics when dispensing medications to their patients. It is important to note that SUD across healthcare professions has existed since the onset of medical, nursing, and pharmacy practices. During the late nineteenth century, opiates, cocaine, and marijuana were legal and widely used widely in many consumer products (Heise, 2003). Morphine was considered to be completely safe and became a habitual practice for many individuals, including healthcare professionals (Heise, 2003). Cocaine was prescribed for minor ailments like toothaches, headaches, and cold symptoms, eventually becoming a drug of choice for healthcare providers (Heise, 2003). Physicians at the time were also experimenting with various anesthesia options, and did so on themselves (Baldisseri, 2007; Heise, 2003). This practice not only contributed to medical advancements, but unfortunately, also contributed to physician addiction. An awareness of the problem was brought about in the early 1970s, when the American Medical Association issued a policy paper "The Sick Physician: Impairment by Psychiatric Disorders, Including Alcoholism and Drug Dependence" (American Medical Association Council on Mental Health [AMA], 1973; Baldisseri, 2007). This served as formal recognition of SUD in healthcare professionals as a problem requiring treatment (AMA, 1973; Baldisseri, 2007).

Nurses also have a long history with SUD and impairment. According to the Nightingale testament, nurses were to inherently exhibit good moral character and were never to use controlled substances (Heise, 2003). Despite this call, there is documentation of substance use dating back to the early years of nursing. However, as a result of societal demands calling for nurses to exhibit good moral character coupled with criminalization 
of controlled substances in the early 1900 s, nurses worked diligently to mask their substance abuse (Baldisseri, 2007). The problem of nurses hiding their problematic use of substances still persists today. The American Nurses Association (ANA) first identified SUD in nursing as a significant issue with a resolution by the 1984 ANA House of Delegates (American Nurses Association [ANA], 1984b; National Council of State Boards of Nursing [NCSBN], 2011). Although the nursing profession formally acknowledged a SUD problem existed among some of its population, it remains one of the most common major regulatory issues in the profession, a consistent issue also with medicine and pharmacy (NCSBN, 2011).

\section{Incidence}

The prevalence of SUD in healthcare professionals has been reported to be anywhere from $6-16 \%$, but the exact prevalence is unknown (NCSBN, 2011). This is because the incidence of SUD in healthcare professions has not been studied by large systematic studies. Identifying the exact prevalence in the healthcare profession is difficult owing to the sensitive nature of the disease. The overall prevalence of healthcare professionals with SUD is thought to be the same as the general population (NCSBN, 2011). While this may be true, it has also been is estimated that substance use in healthcare providers that does not meet the diagnostic criteria for SUD is approximately five times higher than the general public (NCSBN, 2011).

Considering physicians, nurses, and pharmacists all have significant responsibilities in the health of many, this is cause for concern. There is even a greater cause for concern as evidence of impairment in the workplace among healthcare professionals is generally in the very late stages of the disease (Quinlan, 2003). The 
workplace is often the last place to see signs of addiction, as professionals will work very hard to avoid a tarnished reputation. The work environment is an important place to the addicted professional, as in many cases the professional is obtaining their drug of choice from their workplace (Quinlan, 2003). Obtaining the drug and the fix is an important part of the disease process of addiction. If the healthcare provider is caught, they not only face punishment, they lose their ability to obtain their drug of choice.

The general incidence of SUD in healthcare providers may be thought to be similar to the public, however those in healthcare are found to abuse opiates and benzodiazepines at higher rates, probably related to accessibility. Healthcare providers have been found to have much lower rates of marijuana, cocaine, and tobacco abuse than the general public (Baldisseri, 2007). Certain medical and nursing specialties as well as retail pharmacists are identified to be at increased risk for SUD (Baldisseri, 2007; Merlo, Cummings, \& Cottler, 2012; Trinkoff \& Storr, 1998). Emergency physicians have high rates of SUD, psychiatrists tend to abuse benzodiazepines, and critical care nurses have been found to have the highest rates of SUD among nurses (Baldisseri, 2007; Trinkoff \& Storr, 1998). Anesthesia providers, both advanced practice nurses and medical doctors have the highest documented rates of SUD, with $80 \%$ of anesthesia residency programs reporting experience with substance impairment and 19\% report at least one fatality occurrence prior to treatment (Bryson \& Silverstein, 2008). There are unique differences between the general public and the doctors, nurses, and pharmacists that serve the public's healthcare needs. Some of these differences place the provider at risk for development of a SUD. 


\section{Risk Factors Unique to Healthcare Providers}

While there are similar risk factors for SUD for society at large, there are some unique risk factors to healthcare providers. Individuals who are drawn to and elect to pursue a profession in pharmacy, nursing, or medicine set high educational and performance standards, a personality type at high risk for SUD (Baldisseri, 2007; Scimeca, 2008). The practice environment also inherently associated with several risk factors for SUD such as greater access to controlled substances (Kenna \& Lewis, 2008). Healthcare providers know how to covertly self medicate and carry out their role (Bryson, 2012). The knowledge gained in professional school or training does not usually include much about SUD or impairment, which has been found to be another risk for the healthcare professional (Scimeca, 2008; West, 2003).

School is extremely demanding and stressful, and early use of substances in college and residency or other training has been found to be a risk for SUD as a licensed professional. Stress is also present in all the practice environments of nurses, physicians, and pharmacists with long hours, shift work, shortages of physicians and nurses, and the physical, emotional, and mental strain caring for ill people and their families presents (Merlo, Cummings, \& Cottler, 2012; Trinkoff, Zhou, Storr, Soeken, 2000). Despite the similar risks predisposing pharmacists, physicians, and nurses to SUD, each profession may experience different sanctioned consequences.

\section{Statement of the Problem}

SUD presents significant potential for patient harm. Each state protects the healthcare consumer through laws governing the practice of professions that have the potential to present harm if practiced by unprepared, incompetent, or impaired providers. 
These laws allow for the regulation of the practice of nursing, medicine, and pharmacy by requiring all practitioners to be licensed by their state. Each state has a regulatory body that licenses healthcare practitioners and enforces the laws governing that specific practice. The respective licensure boards will ensure educational standards are met, continued competence is maintained, and practice is within the scope and standards of the profession to ensure public safety. Part of ensuring safety of the public is to enforce the law with those practitioners who are found to be impaired. Disciplinary action taken on a license is meant to protect the public from harm, but this very act will also deter a practitioner suffering from addiction from seeking help (Darbro, 2005; NCSBN, 2011).

Fear of punishment, loss of licensure and livelihood, stigma, and a tarnished reputation can inhibit a suffering professional from a fear of seeking help. Fear of punishment is identified by nurses as a significant barrier to necessary treatment (NCSBN, 2011). Substance use disorder constitutes $67-90 \%$ of nursing licensure disciplinary cases (Haack \& Yocum, 2002).

\section{Research Questions}

- What are the differences in disciplinary action between physicians, registered nurses, licensed practical nurses, and pharmacists with substance use disorder?

- Is there a statistically significant difference in punitive or non-punitive punishment of nurses with substance use disorder when compared with their physician and pharmacy colleagues with substance use disorder?

\section{Hypothesis}

The null hypothesis is there will be no statistically significant differences among medicine, nursing, and pharmacy with SUD related licensure discipline. There will be 
statistically significant differences in SUD related licensure discipline among the four professions (Nurses: RN and LPN, Medicine, and Pharmacy). Nurses, both RN and LPN will have more punitive discipline than medicine.

\section{Operational Definitions}

There are many different terms used when discussing SUD in healthcare personnel and the licensure sanctions taken by regulatory bodies. The terms defined below are clarified and defined for better understanding when reading this research study.

Substance Use Disorder (SUD): SUD encompasses both the terms abuse and dependence. SUD is a pattern of compulsive use of a substance that is manifested by recurrent and significant adverse consequences related to the repeated use of substances, with an inability to stop the use despite negative consequences (NCSBN, 2011, p.1). The terms dependence and abuse are no longer used, instead the Diagnostic and Statistical Manual of Mental Disorders, Fifth edition (DSM-5) (American Psychiatric Association [APA], 1994) diagnostic criteria delineates a substance use disorder as mild, moderate, or severe (SAMSHA, 2015). This term encompasses alcohol and other substance use. In administrative regulation of the healthcare professions this term serves as legal grounds for disciplinary action and is one of the criteria entered in the National Practitioner Data Bank.

Practice Act: Legislation enacted by each state to ensure the safe practice of any profession that may present harm to a person. The practice act provides for the legal means to protect the health, safety, and welfare of the citizens of the state. The practice act is law and delineates scope of practice, educational standards, and practice standards, as well as continuing competency for healthcare 
practitioners. Each state's designated regulatory board enforces the law. The Practice Act falls under Administrative Law, not civil or criminal.

Disciplinary Action: Refers to the administrative sanction taken on a healthcare provider's license to practice that particular profession. Terms used by the NPDB for disciplinary action are also adverse action, the terms may be used interchangeably, they mean the same thing. There are a number of different actions that may be taken based on the violation of the law or practice act. Disciplinary action is public information (NCSBN, 2011).

Alternative to Discipline: Promotion of recovery and re-entry to practice by removing the impaired healthcare provider from current practice and providing anonymous treatment with a contract. Should the provider complete the alternative program without a violation of the terms of the contract, no publically available disciplinary action is taken.

Regulatory Board: Consists of the designated professional board: Board of Nursing, Board of Medicine, or Board of Pharmacy. The make-up and powers and duties of a regulatory board are determined by the state's practice act (NCSBN, 2011).

National Practitioner Data Bank (NPDB): A federal data repository for the purposes of reporting adverse action of healthcare providers in the United States (NCSBN, 2011). This data bank was formed from a merger between two previous data banks as a result of the Health Insurance Portability and Accountability Act and has been collecting data since 1990 (Health Resources \& Services Administration, [HRSA], 2016). 
NURSYS- A national database for nursing licensure verification and disciplinary information (NCSBN, 2017). This database is housed by the National Council of State Boards of Nursing and serves as the reporting agent for nurses to the National Practitioner Data Bank.

Diversion: An act that removes a prescription drug from the intended path from the manufacturer to the recipient for other use. For the purpose of this study, diversion is the same as misappropriation, which is stealing of a drug from a patient, healthcare employer, or other source (Berge, Dillon, Sikkink, Taylor, \& Lanier, 2012; NCSBN, 2011).

Impairment: Impairment is the inability to function normally or safely according to accepted professional standards (Baldisseri, 2007). Impairment is the diminished capacity to perform the tasks related to one's occupation by way of health condition, fatigue, or substances (NCSBN, 2011). For the purposes of this study Impairment refers to healthcare providers who are impaired by substances. Punitive Punishment: Significant punishment with the thought that the punishment may alter or deter actions, that the person punished will take responsibility for their actions, and the significance of the action should be met with significant punishment. In the case of licensure discipline, punitive discipline is harsh punishment intended to stop or significantly inhibit the licensee from practicing their profession (NCSBN, 2011).

Non-Punitive Punishment: Lenient punishment which may be done with the idea of rehabilitation of the licensee to successfully return to the profession. The idea 
is punishment should only serve to protect the public, not at the cost of a professional career, as long as a professional may practice their profession safely. Nurse Licensure Compact: States in the United States who have passed state legislation to become party to the Nurse License Compact allow for borderless nursing practice in compact states. The compact also requires by law any disciplinary action taken on a nursing license to be reported to NURSYS who in turn reports to NPDB (NCSBN, 2017). [Appendix B].

Enhanced Nurse Licensure Compact (eNLC) The enhanced Nurse Licensure Compact is an update of the original Nurse Licensure Compact. The compact allows for interstate practice by nurses licensed in the compact. The nurse may practice in each state of the licensure compact without a different license, following each state's respective laws. The enhanced nurse licensure compact provide statutory consensus for uniform licensure requirements.

\section{Purpose of the Study}

Nurses' report feeling they are punished for SUD related violations more punitively when compared to their physician colleagues with the same violations (Shaw, McGovern, Angres, \& Rawal, 2004). The current research study seeks to identify if there are significant differences in disciplinary action between nurses, physicians, and pharmacists with substance use disorder.

\section{Significance of the Study}

Research related to healthcare professionals with SUD has been sporadic at best, with minimal research published in recent years, very little in the last five years. Due to increasing opioid usage and addiction in a constantly changing healthcare delivery 
environment, it is important to study the disciplinary disposition of healthcare providers with SUD. Discipline has been found to be a barrier to treatment for SUD (NCSBN, 2011).

The literature support for this study is dated. This is due to the fact that most evidence is dated. This speaks to the need to evaluate the current state of the problem and answer some of the questions posed by previous research, such as are nurses treated differently than other healthcare professionals? The literature may be dated, but the problem of SUD persists and should be explored in a changing healthcare system.

The affordable care act (ACA) changed so many of the ways healthcare is delivered by all types of healthcare providers. Implementation of the ACA also changes the way patients access and seek healthcare services as well as the way services are paid (Mason, Gardner, Outlaw, \& O’Grady, 2016). There continues to be an increasing demand for care and services, as the health of our country declines and the population ages (Trivedi et al., 2014). This increases the stress and strain on the healthcare system and ultimately the providers. Older literature referenced in this study identified stress and high demands as risks for SUD (Scimeca, 2008; Trinkoff \& Storr, 1998). To compound this changing environment, our country is seeing an increasing use of controlled substances and opioid crisis. We learned years ago healthcare providers are not immune to SUD, so we can estimate an increase in healthcare professionals as well (NCSBN, 2011). Although we know the problem will not go away, research interests have waned in this area. The National Council of State Boards of Nursing (NCSBN), the primary regulatory body for nursing in the United States published a resource book on SUD in nursing, this has not been updated since 2011. The American Nurses'Association (ANA) 
issued a statement on impairment and SUD in the profession of nursing in 1984. This document is no longer available to nurses on the website of the association representative of nurses in the United States, because it was since retired (ANA, 1984b; ANA, 2015). The issue of SUD in nursing has been around since the days of Florence Nightingale and persists, raising the need for continued research (Baldisseri, 2007). The literature available to support much of the need for the study is dated and must be updated and made current to match the state of healthcare delivery by nurses and other healthcare providers.

Current research is necessary to identify possible regulatory or work environment policy or practice changes. This study will provide information and evidence to begin a basis for evidence based regulatory practice changes or to inform new policies. Differences in licensure discipline related to SUD will help us understand the current state of the problem and to provide evidence to support possible practice changes or necessary education for appropriate intervention and treatment. Further, this study may provide a basis for further research to improve regulatory perspectives and to decrease the stigma surrounding SUD in the profession and the associated discipline. Development of educational programs, and regulatory education may evolve from this research as well.

Multiple issues arise in the environment surrounding the impaired nurse, physician, or pharmacist as they continue to practice without intervention. Productivity and morale suffer in the workplace, as the impaired provider has attendance issues, and when present at work, the provider is not functioning well in their job (Trinkoff, Zhou, Storr, \& Soeken, 2000; Shaw et al., 2004). Economically there is a significant impact on 
the employer, whether a pharmacy, hospital, hospice, nursing home, or office (Bryson, 2012; LaGodna \& Hendrix, 1989).

\section{Licensure Discipline Process}

A healthcare provider who is unprepared, incompetent, or practices in an unsafe or negligent manner presents potential danger to the healthcare consumer (NCSBN, 2018b). Licensing and practice laws of each profession provide the licensing jurisdiction the ability to protect their citizens from potentially dangerous healthcare practitioners (NCSBN, 2018a). The grounds for disciplinary action are derived from each professional's state practice act, the statutes governing the practice of healthcare professions in the interest of public safety. Violations of these laws are the legal grounds for administrative action, or grounds for discipline (NCSBN, 2018b).

These administrative laws are enforced only after thorough licensure investigation and legal due process by the professional boards appointed per the respective practice acts of each profession and state (NCSBN, 2018b). It is only after the finding of a violation and a disciplinary order that a violation is entered into the NPDB (HRSA, 2016). Like criminal law, administrative violations and actions are public record. Each disciplinary action is based on a final legal order following a settlement or hearing (NCSBN, 2018b). Each and every licensee has a right to appeal the disciplinary action as part of due legal process (NCSBN, 2018b). All of the records contained in the NPDB are the final disciplinary action following all investigative proceedings, settlement agreements, hearings, and appeals (HRSA, 2016; NCSBN, 2018b). 


\section{Punitive Versus Non-Punitive Discipline}

While any discipline taken on a professional license can affect the professional's reputation or career, some forms of discipline are more severe than others. The punitive nature of the disciplinary action is compared in this study using the same reason (basis) for discipline to be taken. Revocation and suspension are considered the harshest form of disciplinary action as both interfere with the ability to practice a profession altogether for a period of time (NCSBN, 2018a). Probation is a difficult sanction, although less punitive. The licensee on probation must follow strict terms and conditions set by the professional board to practice their profession (NCSBN, 2018a). A censure or warning is considered much less harsh and the licensee is still able to make a living practicing their profession. Although censure is formal discipline and must be reported to the databanks, it does not impede practice or place any restrictions on the provision of healthcare services (NCSBN, 2018a). Disciplinary action may be intended to protect the public, but may be seen as punishment rather than protecting patients as the provider recovers. In this data analysis, each type of discipline is compared profession to profession.

\section{Alternative to Discipline and Discipline}

The danger presented to patients by the licensed healthcare professional diagnosed with SUD or practicing their profession impaired is the reason for disciplinary action. The disciplinary approach ultimately penalizes professionals to prevent them from further dangerous practices (Monroe, Pearson, \& Kenaga, 2008). Licensure discipline also serves to protect the healthcare consumer by making known the practitioner is unable to safely practice the profession due to addiction or impairment. Disciplining the license of a practitioner does not provide for treatment or assistance with SUD (Darbro, 
2005; Monroe et al., 2008). Disciplinary approaches vary from jurisdiction to jurisdiction, but many physicians, nurses, and pharmacists find their licenses revoked, suspended, or have probationary terms that can affect their future ability to practice, even if the licensee does successfully rehabilitate (Bryson, 2012; Monroe et al., 2008). Drug rehabilitation is difficult to pay for without employer-based health insurance, should the practitioner lose their job when they are disciplined (Monroe \& Kenaga, 2010). If the healthcare provider is able to secure employment after rehab, there is professional stigma involved, difficulty in securing malpractice insurance, and the monetary penalties can be severe (Darbro, 2005; Monroe et al., 2008).

Alternative to discipline programs are designed to quickly and safely remove the healthcare provider from an impaired practice situation and provide options for appropriate treatment (Bryson, 2012; Monroe et al., 2008; NCSBN, 2011). If the healthcare provider is able to successfully adhere to guidelines set forth by the alternative to discipline program, they may return to practice without licensure discipline (NCSBN, 2011). Alternative to discipline programs do not automatically report healthcare providers to national data banks or to the Office of the Inspector General (NCSBN, 2011). If a healthcare professional is reported and disciplined, further practice may be difficult. The alternative approach to treatment has been found to be a more effective method of public protection, quickly and confidentially providing needed help. The provider can seek appropriate treatment without fear of repercussion and loss of reputation and livelihood (Bryson, 2012; Monroe et al., 2008). The time it takes to remove the professional from practice, to prevent harm, is also significantly less with alternative programs. Getting the impaired provider admitted to treatment within one to 
two weeks is the focus, whereas with the disciplinary approach there is an average of two years from investigation to treatment (Bryson, 2012; Monroe et al., 2008). Physicians, nurses, and pharmacists who are able to get rehab via an alternative program are treated for a chronic disease, decrease the related stigma, and provide the needed support in recovery and return to practice (Darbro, 2005; NCSBN, 2011).

Disciplinary action taken on healthcare providers can be a barrier to treatment for those suffering from SUD. The provider will continue to jeopardize the health, safety, and welfare of those in their care, as well as their own health and well-being as they work very hard to hide their SUD for fear of being found out. Despite the same risks and propensity to SUD among the professions, there may be differences in how SUD is handled by regulatory bodies. There is limited research regarding the differences in the handling of SUD among professions. If nurses are treated more punitively, the risks to patient lives are significant, as nurses have the largest number as compared to the other healthcare professions, and many provide direct patient care (NCSBN, 2011). Punitive punishment has the potential to cause nurses suffering from SUD to not seek treatment. Further, nurses, physicians, and pharmacists have been found to have much higher rates of recovery than the general public (Bryson, 2012). Similar rates of recovery among healthcare professionals mean there is no reason to discipline one more punitively than another. This study will determine the disciplinary disposition of pharmacists, nurses, and physicians to identify if there is consistency or significant differences across different professions with the same disease process. 


\section{CHAPTER 2}

\section{REVIEW OF LITERATURE}

Substance use disorder (SUD) in healthcare professionals is a multi-factoral problem. Related to the unique nature and presentation of the disease in the health professions, research on SUD in the health professions has been sporadic at best and extremely limited in the past five years. Existing literature focuses on risk factors, attitudes, prevalence, education, and identification and intervention. There is little research exploring the differences in disciplinary action between the professions.

\section{Prevalence}

Prevalence of SUD in the healthcare professions is difficult due to the sensitive nature of the disease. Many prevalence studies have been done via self-report, in which the data is only as good as those reporting (Polit \& Beck, 2017). Due to the fear of disciplinary action or denial of a problem altogether, there are cases that will not be counted. The prevalence of SUD in the healthcare professions is generally thought to be about that of the general population (NCSBN, 2011). With the use of a survey tool, a convenience sample of 4064 Canadian nurses, Kunyk (2015) found the prevalence of nurses with SUD is consistent with the general population. This was a self-report survey with expressed limitations with the geographical distribution and sampling method and thus generalizing the results. Physicians are thought to have the same SUD prevalence as the general population, and were also found to have higher rates of opioid use than the general public (Merlo \& Gold, 2008). Prevalence rates aside, SUD has been an ongoing problem for many years, and lower or higher rates than the general population, requires attention to protect patients and improve the health of the physician, nurse, pharmacist, or 
any healthcare provider. All physicians, nurses, or pharmacists may be susceptible to SUD because of the unique risks presented by their work environment.

\section{General Risk Factors}

\section{Genetics}

Propensity to substance use may be in the background of individuals well before they choose their occupation (Scimeca, 2008). Genetic predisposition, environment, and personality traits are all independent risk factors separate of one's choice of career (NCSBN, 2011; Scimeca, 2008). Genetic predisposition has been well documented as a risk factor for substance use, addiction, and dependency (NCSBN, 2011). A family history of chemical dependency places one at risk to have a problem with substance use. However, $40 \%$ of risk stems from genetic predisposition, and the other $60 \%$ comes from environmental factors (Bryson, 2012).

The environment a child is raised in becomes their perception of normal, even if "normal" is dysfunctional. Dittman (2008) explored the experiences of male nurses recovering from chemical dependency using a qualitative research approach; all of the men surveyed in her study identified their addictive family history as a contributing factor to their own SUD. A study conducted using a cross-sectional survey design with a sample of 479 dentists, nurses, pharmacists, and physicians in a northeast state found that having a significant family history of drug and alcohol problems determined a higher risk

for SUD in pharmacists and nurses over physicians or dentists (Kenna \& Wood, 2005).

\section{Personality}

Personality traits, such as impulsiveness, risk-taking, and perfectionism are all risk factors for chemical dependency (Bettinardi-Angres \& Angres, 2010; NCSBN, 2011; 
Scimeca, 2008). Healthcare professionals in general are high-achieving, the same personality traits which make them successful in their work may predispose some to substance use disorder (Baldisseri, 2007; Bryson, 2012; Scimeca, 2008). The study by Dittman (2008) also found this personality type in most of her sample of recovering nurses from the Florida Impaired Nurses group. The majority of research studies related to SUD in healthcare providers were conducted in the 1980 s, consistently showing this personality type is a predictor of SUD.

Many healthcare professionals turn to the use of the same pharmacological agents they administer, prescribe, or dispense, seeing the positive therapeutic effects the drugs have on their patients (Merlo, Trejo-Lopez, Conwell, \& Rivenbark, 2013). Some healthcare providers see these same drugs as a way to help them personally cope or achieve a similar desired personal positive outcome (Merlo et al., 2012). Trinkoff and Storr (1998) found SUD risk related to work specialty. Nurses who are driven to work in high-stress and high-adrenaline areas possess specific character traits, which place them in the high-risk category for substance use disorder. A cross-sectional descriptive survey study of various healthcare professionals found many nurses thought of themselves as pharmaceutically invincible, or their knowledge gave them power and control over the use of the substance (Kenna \& Lewis, 2008).

The very same personality traits that place healthcare providers at risk for SUD, are also the reason the healthcare professionals have high rates of recovery. A five-year longitudinal cohort study revealed physicians have excellent recovery rates, $78.7 \%$ were still licensed and employed five years after treatment (McLellan, Skipper, Campbell, \& DuPont, 2008). The research sample was taken from 16 states in the US, including 904 
recovering physicians (McLellan et al., 2008). The study found there was only a 19\% relapse rate among all the physicians during this five-year time (McLellan et al., 2008).

Nurses have higher rates of recovery than the general population, with relapse rates of approximately $40 \%$ versus the general population at $75 \%$ (Darbro, 2005). Other estimated recovery rates for all healthcare providers with SUD are somewhere around 78\% (Bryson, 2012). Healthcare providers are highly motivated, high achieving, extremely knowledgeable professionals who have worked very hard to train for their chosen career and to obtain their licenses (Bryson, 2012). Therefore, the majority of addicted providers are also highly motivated to recover. The healthcare professionals recovering from SUD have the requisite knowledge, skills, and drive necessary to successfully recover (Bryson, 2012).

\section{Early Use}

Early use of substances for recreational purposes, before or during professional school, is another contributing factor mentioned by all licensed healthcare professionals in recovery (Angres, Talbot, \& Bettinardi-Angres, 2012; NCSBN, 2011; Merlo et al., 2013). The young brain is more susceptible to the effects of substances, and therefore the younger one is when using substances, even if only for fun, places them at increased risk (Baldisseri, 2007; Baldwin, Bartek, Scott, Davis-Hall, \& DeSimone II, 2009; Scimeca, 2008). Early use of substances has been associated with development of substance addiction. The vast majority of healthcare professionals in recovery began using substances prior to entering professional school. Merlo et al. (2013) surveyed 105 healthcare professionals in recovery and found a large majority, $94 \%$ and $64 \%$ used drugs and alcohol respectively, prior to beginning their professional schooling. While the 
reasons for initial use of substances mirrored the general public (recreational, experimental use), the reasons for continuing to use the substances into their professional career was different (Merlo et al., 2013). The healthcare professionals identified continued use to offset stress and to avoid withdrawal symptoms (Merlo et al., 2012).

\section{Work Environment}

Healthcare professionals share risk factors that contribute to the development of SUD (Angres et al., 2012; Bryson, 2012). Both physicians and nurses often work long, demanding hours with increasingly limited resources in high stress environments (Bryson, 2012; Trinkoff \& Storr, 1998). Pharmacists cite stressful or unpleasant work environments as a contributing factor to SUD (Merlo, Cummings, \& Cottler, 2012). Merlo et al., (2012) found $60 \%$ of pharmacists are able to manipulate drugs easily to get a desired response. Nurses have knowledge of medication administration and the desired response to medications (NCSBN, 2011). Physicians identify the ready availability of drugs to treat pain, anxiety, and/or depression and also to enhance their professional performance as reasons for use of substances in their work environment (Angres et al., 2012).

Stress is inherent in the healthcare delivery environment, which may be attributed to long hours, excessive work, limited staff, and fast-pace environments (Bryson 2012; NCSBN, 2011). The National Institute on Alcohol Abuse and Alcoholism [NIAAA] (2008), states that problems with alcohol may begin as people turn to alcohol to cope with stress. Initially this helps to relax and provide positive feelings, but long-term use can increase the risk for alcohol dependency (NIAAA, 2012). According to Trinkoff \& Storr (1998) high-stress nursing specialties are at high risk for substance use disorder. 
This study was an anonymous self-report of nurses having a large sample size of 4,438 nurses. This study found nurses working in the emergency room, critical care areas, and oncology used substances at higher rates; this could be attributed to more than merely stress. Previously, personality was discussed as a risk factor along with nurses working in specialty areas that generally possess a specific high-risk personality type. While the study rendered results as to which specialty areas to address, it was limited by the selfreporting method of previous year substance use. Healthcare providers in recovery cite thriving under pressure, their unhealthy response to pressure, and an early introduction to substances as reasons for use (Bryson, 2012). Satisfaction and support in the work environment may decrease stress for nurses and is also known to assist those in recovery to maintain their sobriety. Workplace stress was one of the identified themes in the grounded theory qualitative study (Darbro, 2005). Workplace satisfaction and social support were found to be protective to nurses against substance use disorder (Darbro, 2005).

Using a grounded theory approach, a similar study of recovering pharmacists also produced the theme "stressful/unpleasant working environment (Merlo, Cummings, \& Cottler, 2003). Most pharmacists identified using substances to cope with their stressful jobs (Merlo et al., 2003). Physicians in recovery also identify the same stressful job environment as one of the reasons they used substances (Merlo, Singhakand, Cummungs, \& Cottler, 2013). This data was derived from interviews with 55 physicians in a state drug monitoring program, grounded theory drove the qualitative thematic analysis (Merlo, Singhakand et al., 2013). 


\section{Access and Diversion}

Access is one of the occupational conditions placing healthcare providers at risk for SUD. A secondary data analysis of the Nurse Worklife and Health Study was conducted and resulted in the identification of the direct link of access to SUD (Trinkoff et al., 2000). There was a statistically significant difference between nurses with access to controlled substances and less access and SUD (Trinkoff et al., 2000). The more access, the more likely the nurse is to have SUD (Trinkoff et al., 2000).

Pharmacists were found to have extensive methods of drug diversion. Over $80 \%$ of pharmacists admitted to using a prescription drug that was not prescribed to them (Merlo, Cummings, \& Cottler, 2012). Group discussion interviews with recovering pharmacists found they were able to divert drugs for their own personal use by at least six different methods (Merlo, Singhakand, Cummings, \& Cottler, 2012).

Physicians identify using any means to procure their drug of choice, mostly writing prescriptions or using their privileges to access medications (Merlo, et al., 2013). The three different healthcare professions have different ways of acquiring substances from their workplace based on their access and professional duties. Even with the differences between professions, there should be consistency in the regulatory management of SUD among physicians, nurses, and pharmacists.

\section{Education}

Lack of SUD education of all healthcare providers contributes to the idea of addiction as a moral failing rather than a disease, and also decreases the ability of colleagues to identify and report impairment in their workplace (Baldwin, Davis-Hall,

DeSimone II, Scott, Agrawal, \& Reardon, 2008; Bettinardi-Angres \& Bologeorges, 2011; 
Merlo et al., 2012; NCSBN, 2011; Beckstead, 2005; Lillibridge, Cox, \& Cross, 2002; Monroe \& Kenaga, 2010). Pharmacists specifically identify the lack of education as a contributing factor to a condoning culture of self-treatment potentiating SUD, and further, lack of support for SUD treatment (Merlo et al, 2012). Lack of training is also identified as a significant issue for nursing and medicine in the practice environment, where the impaired provider may be unwilling or unable to identify a colleague in need of help, allowing further impaired practice (Beckstead, 2005; Lillibridge, Cox, \& Cross, 2002).

A nationally representative survey of 2938 physicians practicing in the United States found $64 \%$ of physicians felt professional responsibility to report impairment, yet many do not report impairment (DesRoches, Rao, Fromson, Birnbaum, Iezzoni, Vogeli, \& Campbell, 2010). Grower \& Floyd (1998) addressed knowledge of nurses related to substance use disorder and how likely nurses are to intervene with a peer suffering from substance use disorder. A random sample of 142 nurses found less than half of nurses had adequate knowledge of addiction and most would not be able to identify a peer with substance use disorder (Grower \& Floyd, 1998). Beckstead (2005), found the odds of not reporting substance use signs and symptoms by a co-worker are five to one. BettinardiAngres \& Bologerges (2011) found nurses do not report suspicions, as they do not feel they are able to identify an impaired colleague. Furthermore, nurses identified a lack of knowledge regarding peer assistance and other alternative to discipline programs (Monroe \& Kenaga, 2011).

Lillibridge et al. (2002) identified the lack of education in substance use disorder in undergraduate education as a primary reason for ongoing stigma, lack of early 
identification of peers, and lack of support in return to practice. Nursing students also report inadequate substance abuse education during their initial licensure programs (Baldwin et al., 2011). On the other hand, student nurses with education related to substance use disorders tend to view the issue with much more compassion (Boulton \& Nosek, 2014).

\section{Summary}

Despite the similar risks and rates of SUD in medicine, nursing, and pharmacy, differences exist in the way the addicted professionals are treated once identified. High societal expectations and cultural attitudes place doctors on a pedestal (Angres et al., 2012). The greater value placed on physicians by society creates a quiet, private environment for recovery, while nurses tend to be publicly sanctioned (Angres et. al, 2012). Physicians also tend to be self-employed, with institutions dependent on their services for reimbursement. Nurses and pharmacists are generally employees of organizations that may view these types of providers as an institutional liability (Merlo et al., 2012; NCSBN, 2011).

When compared to physicians, nurses report more punitive, severe sanctions as a result of their SUD (Shaw et al., 2004). Perhaps one of the most striking differences between nursing and medicine is nurses are found to be much more symptomatic than physicians upon admission to treatment (Shaw et al., 2004). Nurses tended to practice a bit longer in an impaired state and there was statistically significant data to show physicians received more treatment for SUD (Shaw et al., 2004). This research supports the need to determine the differences in disciplinary action to identify ways to help nurses seek treatment consistent with their other healthcare colleagues. 


\section{CHAPTER 3}

\section{THEORETICAL FRAMEWORK}

Explaining the differences between the healthcare professions related to SUD licensure discipline is complex. Administrative laws governing the practice of the professions of medicine, nursing, and pharmacy exist to protect the consumer of healthcare from providers who are impaired, unprepared, or incompetent (NCSBN, 2011). Regulatory boards seek to protect their consumers from dangerous practitioners. Each profession regulates itself in all licensure jurisdictions. Punitive or non-punitive disciplinary action comes from within the profession, as regulatory boards are made mostly of peers. Therefore, disciplinary action taken on licensed healthcare providers with SUD can only be attributed to the philosophy of discipline held by each respective profession.

Physicians, nurses, and pharmacists are groups functioning with rules, standards, and policies, within defined scopes and roles working in larger institutions serving society. There are many social interactions among the different professions as well as with society as a whole. Social hierarchies have historically existed through healthcare, with physicians having higher social status and power. However, there are no social considerations between these professions when it comes to regulation because regulatory boards only have authority via administrative law to regulate their own profession. The disciplinary action taken on a professional licensee has to do with the perspectives of SUD held by those taking the action. SUD can be viewed as criminal, dangerous, or a disease both by individuals and the board as group. These underlying views influence the way healthcare professionals with SUD are disciplined. These social views, or stigma 
surrounding a healthcare professional or person with SUD have the ability to explain differences in licensure discipline between the different professions.

\section{Goffman's Theory of Stigma}

The theoretical framework used to describe this research study is Irving Goffman's (1963) theory of stigma. This theory originated in sociology, and due to the separate regulation of physicians, nurses, and pharmacists, there are no inter-group sociological issues impacting differences in licensure action. Physicians, nurses, and pharmacists have different roles and scopes of practice, delivering healthcare services in a wide array of organizations, and different practice environments. One specific organizational motivation or relations theory will not be able to explain differences in how these providers are disciplined because there are varied social and environmental factors, Any differences in disciplinary action taken, either punitive or non-punitive would be largely based on the philosophy of discipline of SUD of the professionals appointed to the regulatory boards. A broad sociological theory is therefore necessary to frame the differences in discipline among separate, specialized groups providing different types of healthcare services to society. Goffman's (1963) theory of stigma describes how many of these concepts related to the disciplinary outcome could differ in highly regarded social groups, like healthcare providers regarding a disease process such as SUD that carries a negative social connotation.

Stigma is defined as a mark separating individuals from one another based on a social attribute defined as abnormal (Goffman, 1963). The word stigma dates back to ancient Greece when criminals, slaves, or other immoral people were cut or marked to show society to avoid them (Goffman, 1963). Stigma is viewed by society as a negative 
attribute, identifying a person or group who is different. People who are stigmatized usually have a spoiled identity, are devalued, and disapproved of by larger society or the larger group (Goffman, 1963). One stigmatized quality can be viewed as "tainted" and reduced in worth to the larger group, excluding those with this status (Bos, Pryor, Reeder, \& Stutterheim, 2013).

Goffman (1963) identifies three types of stigma: physical, blemishes of individual character, and tribal (referring to group affiliation). In the context of this study, stigma arises from the blemish of the individual's character. Individual character stigma is an attribute that results in social disapproval, a difference seen in a negative way that labels a person as deviant and discredits their identity (Bos, et al., 2013; Goffman, 1963). SUD is usually viewed as more of a criminal issue than a disease process in many instances and the person affected deserves to be socially denounced and punished (Livingston, Miline, Fang, \& Amari, 2011).

Stigma may impact healthcare providers with SUD in two distinct ways. Social stigma occurs when social groups have formed stereotypes and negative reactions based on different qualities or attributes of individuals such as a disease process (SUD) or social status (doctor) (Livingston et al., 2011). Structural stigma refers to the procedural aspects of an institution, like policies, regulations, or rules (Livingston et al., 2011). Rules and laws govern society and establish social norms. Organizations and institutions maintain these norms with various rules and laws and professions maintain high integrity with established professional standards. Following social norms is viewed as positive, expected, and acceptable behavior. A social group or institution may view a violation of social norms negatively, especially when there is a perceived choice (Bos, et al., 2013). 
Structural stigma may limit the amount of stigmatized individuals or groups within them by the policies or rules (Livingston, et al., 2011).

Society in general views SUD as a moral and criminal issue. The general views of SUD held by society may influence how employers identify these behaviors as deserving of disapproval and condemnation, making rules consistent with the appropriate social order of expected norms of the provision of health services. A healthcare provider with SUD also presents danger to patients, and to regulatory bodies as a criminal offense requiring discipline. Following institutional or regulatory action, a professional is reported to a publically available database with the premise of protecting society from further dangerous or deviant behavior. Furthermore, a provider with SUD demonstrates behavior socially and professionally inconsistent of what a patient should expect in behavior of a physician, nurse, or pharmacist. Stigma ascribed to a licensed healthcare professional with SUD has the potential to have a significant impact on their life by way of their employment, licensure, livelihood, and social identity.

Goffman (1963) identifies the person who has a stigma placed upon them as different in an undesirable way, and those affiliated with these stigmatized people are also at risk socially. This has come to be known as associative stigma (Pryor, Reeder, and Monroe, 2012). People in the same social circle as a person found to have a stigmatized attribute, like a nurse with SUD, they are motivated to socially exclude them to save the identity of themselves (Pryor, et al., 2012). This exclusionary stigma marks the person in the "out" group, and in turn they are associated with a negative stereotype. Stereotypes are the end product of labeling, and then become society's view of that person with the specific negative attribute (Major \& O’Brien, 2005). Labeling is the negative 
identification of the social out-group, identifying separateness of the in-group and outgroup, causing loss of status for those labeled (Goffman, 1963; Major \& O'Brien, 2005). Labelling is a part of the process of stigma (Goffman, 1963; Major \& O’Brien, 2005). Prejudice forms from being exposed to society's stereotypes, agreeing with the negative views of a person with this trait (Major \& O’Brien, 2005). Prejudices are formed from society and collectively influence the behaviors and action taken on stigmatized individuals (Major \& O’Brien, 2005).

\section{Disease Related Stigma: Substance Use Disorder}

The stigma attached to certain disease processes has existed for many years. Some diseases and health conditions have the potential to cause exclusion, rejection, judgment, and devaluation of a person or group (Scamber, 2009). Health-related stigma is society's way to discourage dangerous, unhealthy, or socially unacceptable behavior. Some stigmatized diseases include Human Immunodeficiency Virus and Acquired Immune Deficiency Syndrome (HIV/AIDS), schizophrenia, and SUD (Scambler, 2009). The causes of the illness may be socially or morally unacceptable or symptoms of the disease may make the person socially different or invoke fear of contagion, causing social avoidance or judgment (Scambler, 2009). Stigma-related to a disease like SUD stems from social norms because of the etiology and subsequent behavioral manifestations of the disease. To the majority of society, a person must make the choice to use the substance initially, and many of the behaviors associated with alcohol use and illicit substances are seen as immoral and criminal (Bos, et al., 2013). Therefore, there is a choice to use substances and to be immoral and break the rules. The person may be viewed as flawed or afflicted by a disease by their own choosing. The person with SUD 
also is thought to have the choice to continue to use the substance and the opportunity to take corrective action. This character flaw can cause spoiled identity, especially when the person is part of a highly regarded ethical profession and should have the knowledge to avoid such a disease by choosing wisely to not becoming an addict (Goffman, 1963). Furthermore, the healthcare professional should know they have a problem and stop placing themselves and others in danger, because this is part of what they do for a living. Any trusted healthcare professional should avoid immoral, dishonest behaviors, as they do not coincide with the standards and societal views of these professions (Livingston, et al., 2011).

\section{Professional Code of Ethics}

Nursing, pharmacy, and medicine have a long history of trust from the larger society, as well as high professional standards they have set for themselves. Nursing's Social Policy Statement identifies that nurses have a contract with society to provide care within the scope, standards, and laws established by the profession (American Nurses Association [ANA], 2010). Nurses should function at a high level of professionalism within the laws established by nurse practice acts (ANA, 2010). The Code of Ethics for Nurses (2015) also establishes a high standard of ethics for nurses to practice the profession maintaining responsibility and accountability to the public for nursing care rendered. The social contract between nurses and the public works both ways, as nurses have been ranked as the most honest and ethical profession in the United States for 17 consecutive years (Brenan, 2018).

Medical doctors and pharmacists follow the nurses at number two and three, respectively (Brenan, 2018). The Code of Ethics for Pharmacists establishes the 
principles and responsibilities of pharmacy practice (American Pharmacy Association [AphA], 1994). Article IV of the pharmacy code of ethics holds pharmacists to a high standard of honesty and integrity (APhA, 1994). The code of ethics further reads, "A pharmacist avoids discriminatory practices, behavior or work conditions that impair professional judgment, and actions that compromise dedication to the best interests of patients" (APhA, 1994). The American Medical Association (AMA) identifies physicians shall uphold professional honesty and report any in the profession who may have competency or character deficiencies (2016).

A healthcare provider that diverts medications or has an active SUD would be in direct violation of any of these professional codes. A licensed healthcare provider in any of these professions causes concern for upholding the high standards of the professions. Disciplinary action could be taken to keep a provider on the outside of the profession as ethically the nurse, physician, or pharmacist no longer fits in. Healthcare professionals with SUD may be viewed as dishonest or lacking willpower by both their profession and society (Bryson, 2012; NCSBN, 2011).

Writing false prescriptions to obtain medications for self use or diversion of medications for personal use is viewed as dishonest (Angres, Talbott, \& BettinardiAngres, 2012). These healthcare professionals are educated and trained with specific knowledge, so they should know better than to get hooked on drugs. Society holds these professions to a high standard and place immense trust in their knowledge and skills. All professions take their duties and this social contract seriously and work to uphold the high standards society expects of them. To society as a whole, a dishonest person in a trustworthy profession is a difficult thought. Physicians, nurses, and pharmacists have 
high expectations to uphold high standards, be trustworthy, and provide high quality care. The profession can maintain this reputation by punishing those who break the rules and potentially deter any future unprofessional behavior. The basis of regulating professional licensure with SUD is based on the views of those on these regulatory boards in upholding these social contracts, high standards, and following the rules and laws.

\section{Stigma and Discipline}

Social order is maintained by rules. Rule following is the expected norm and rule breaking is a deviation from the socially expected appropriate behavior delineated by the rules. Punishment for breaking rules can mark a person as deviant, not conforming to the norms expected by society (Goffman 1963). Discipline of any type is meant to maintain social order and deter socially unacceptable behaviors or to protect people from dangerous actions (Warr, Meier, \& Erickson, 1983). Discipline of healthcare professionals is no different. Administrative laws enacted regulating the practice of healthcare professionals exist to protect the healthcare consumers in each state from those professionals who may be dangerous or incompetent (NCSBN, 2011). Any licensed professional who is disciplined in any profession for any reason has the potential to be marked by the public and/or their profession as unable to practice skillfully and competently; a hazard to patients, the profession, and organizations (Darbro, 2005; NCSBN, 2011).

Goffman (1963) identifies those marked as deviant may get labeled as unwanted or undeserving to be part of a group (Bos, et al., 2013). Any violation of the high standards of each profession and the significant trust of the public can be harmful to the reputation of the individual personally, professionally, or both. The mark of disgrace of 
not following the professional rules and breaking the laws governing the profession can be professionally significant, especially where the names of the disciplined are publically released and reported to government agencies. Whether or not it is a desired outcome of discipline, the professional may find themselves as an outsider, as they no longer meet the high expectations of character to be a part of the profession. Discipline related to SUD affects the ability to be trusted, gain employment, and practice one's chosen career (NCSBN, 2011).

SUD has widely accepted negative social connotations that are culturally endorsed (Livingston, et al., 2011; Scambler, 2009). This acceptance has a deep seeded history forged in policy. The criminalization of drug use began in the 1970's when President Nixon declared the first war on drugs (Doweiko, 2015). This continued into the 1980’s and 90’s, worsening when Nancy Regan began the "Just Say No" media campaign (Doweiko, 2015). The campaign influenced society to identify drug use with weak-willed criminal types. SUD in a healthcare professional has the potential to be significantly stigmatizing with the high ethical standards and they have significant knowledge as a basis to know better than to say "yes" to drug use (NCSBN, 2011).

The stigma related to SUD in healthcare providers is significant when evaluating licensure discipline according to Goffman's theory (1963) because there are multiple factors that would potentially impact the disciplinary decisions and influence the licensure outcomes. SUD is a disease with moral and criminal connotations, manifesting potential unsafe behaviors presenting harm to others (vulnerable patients). The high standards involved with the profession and the need to protect the patients from danger, amount to the need or desire to discipline a licensed professional. The discipline is 
dependent on the philosophy of the professional board, the high standards placed on the profession by society. There are also normative beliefs and attitudes toward the disease influenced by larger society impacting each decision maker evaluating the gravity of the situation and taking action.

\section{Discipline and Society}

When a healthcare provider is disciplined the regulatory purpose is public protection. Punishment is the infliction of some form of pain or undesirable outcome for a violation or misdeed (Garland \& Sparks, 2000; Vito \& Maahs, 2017). There are different philosophies regarding the outcomes of formal disciplinary action. Depending on how this is conceptualized, both have the ability to describe what may happen with the outcomes of licensure discipline. Retribution is the punishment that will fit the crime (Garland \& Sparks, 2000; Warr, Meier, \& Erikson, 1983). Human beings are thought to be of free will and make sound choices based on morals and the rules and laws (Garland \& Sparks, 2000; Vito \& Maahs, 2017).

One philosophy of discipline hinges on the person making a choice to upset societal balance should be disciplined accordingly based on the significance of the crime (Warr, et al., 1983). In the case of SUD in licensed healthcare professionals, there is a choice to use substances that may impair one's ability to safely provide services within the scope of practice. Based on this immoral and unsafe decision, discipline should be taken to keep this person away from patients. Further, this theory can describe the need to keep the immoral, impaired, substandard, law violating person on the outside of a profession to uphold the high ethical standards of the profession. Essentially this person 
does not fit in to the "norm" of this social group and the profession should avoid having such people be practicing.

A second philosophy of discipline seeks to deter criminal activity with established and known punishments (Garland \& Sparks, 2000). Those punished for a crime serve as an example to the larger group of how not to act and what not to do. The anticipated pain of the discipline should help the person to make a decision against committing the crime in the first place (Garland \& Sparks, 2000). Healthcare providers should know better than to make the decision to use substances that may impair their judgment. Most are fearful of the potential consequences of even one bad choice with a substance (Scimeca, 2008; West, 2003). Many providers have a strong fear of the consequences of a misstep, diligently working at the highest standards to avoid loss of livelihood and identity as a healthcare professional, especially with something they feel could be avoided like SUD (Darbro, 2005; Lillibridge, Cox, \& Cross, 2002).

Disciplinary action can also cause collateral damage. Discipline may cast out those healthcare providers identified as tainted by violating the ethics, behaviors, and or high standards set forth by the profession. If a professional is seen as worth rehabilitating, the disciplinary action may be less punitive. There are significant shortages of healthcare professionals in certain areas, cause for keeping these already skilled, knowledgeable providers practicing their chosen profession if they can rehabilitate and safely return to practice (Darbro, 2005; NCSBN, 2011). Healthcare professionals found to have SUD tend to be skilled, high-achieving practitioners (Bryson, 2012; NCSBN, 2011). There is evidence to support early identification and treatment may be beneficial to these healthcare professions because early treatment decreases prolonged impaired practice 
decreasing the risk for harm to patients (Bryson, 2012; Darbro, 2005; NCSBN, 2011). Healthcare providers have been shown to have extremely high recovery rates, and if confidential treatment is offered early in the disease process, there are better outcomes (Bryson, 2014; Darbro, 2005). Confidential treatment spares the reputation of the healthcare provider and saves patients from potential harm (NCSBN, 2011).

People directly affected by stigma may feel shame and want to avoid stigma to stay as an insider to the group (Goffman, 1963). Shame and fear of blame can be a significant obstacle to seeking assistance for SUD in the healthcare professions. Stigmarelated fears have the potential to drive healthcare professionals into hiding, furthering the severity of the SUD (Bryson, 2012; Scimeca, 2008; NCSBN, 2011). Recovering health professionals identify fear of loss of licensure, livelihood as well as professional identity as reasons to hide their problems with alcohol and substances (Darbro, 2005; Dittman, 2008). The stigma placed on SUD from those in a profession may be a cause for punitive disciplinary action, casting out the morally wrong or substandard care providers from the profession so as not to affiliate the profession with these character-flawed individuals.

Stigma causes social isolation and the stigmatized person would be cast out of the norm group (Goffman, 1963; Scamber, 2009). Differences in the way the professions approach discipline may be consciously and subconsciously based on how they view their own professional standards in relation to the disease manifestations of those in their own profession. Based on these views, in response to a case of SUD the outcome could be a disciplinary response to protect their own profession and uphold standards. Protecting the profession as well as protecting the public means casting out those who are seen as bad in 
violation of the professional standards. The provider who is impaired or has an addiction should be marked to prevent any potential for harm. If those that make up the disciplinary body view the person with a drug problem in the same light as society as a whole, the punitive nature of the licensure sanction would follow more of a criminal justice approach. Deterrence and removal would be an approach to salvage and/ or maintain the high standards of the profession to the consumers in society. Licensure discipline, no matter how punitive, will mark a person as having an SUD, furthering stigma with coworkers and society as a whole. They are either seen as bad, unprofessional, or dangerous.

\section{Lack of Education}

There is evidence addressing the lack of education of healthcare providers as a contributing factor to SUD in the healthcare professions (Boulton \& Nosek, 2014; Martinez \& Murphy-Parker, 2003; Neville \& Roan, 2014). Nurses were found to have negative perceptions of people with SUD and identify a lack of knowledge about the disease as a contributing factor (Neville \& Roan, 2014). General lack of knowledge in healthcare providers contributes to negative views toward those with SUD in both patients and professionals (Baldwin, Davis-Hall, DeSimone II, Scott, Agrawal, \& Reardon, 2008). There is some evidence to support more education pertaining to SUD as a disease in professional school will lead to a more compassionate response by healthcare professionals. More education for the nurses, physicians, and pharmacists has the potential to change some of the stigma of the disease and decrease negative views toward patients (Boulton \& Nosek, 2014). 
Even with favorable views of SUD as a disease process, the provider found to have been taking medications for themselves may still be disciplined in a punitive way. Regulation of the professions in the interest of public safety requires some intervention to safely remove the impaired provider from practice to prevent any harm or injury. Some of these providers have taken medications from their employers or patients, and have done procedures or monitored a patient under the influence of substances. There may still be a negative view of a professional with SUD as bad for the profession and an innate need to isolate them from the profession for the greater good. This is consistent with the description of stigma by Goffman (1963). 


\section{CHAPTER 4}

\section{METHODS}

\section{Data Source}

A secondary data analysis design was used to conduct this research using disciplinary licensure data from the National Practitioner Data Bank Public Use Data File (NPDB). The NPDB is the federal repository containing adverse licensure and malpractice information regarding healthcare practitioners (United States Department of Health and Human Services [DHHS] \& Health Resources \& Services Administration [HRSA], 2018). The NPDB was established to provide information to healthcare entities and other agencies regarding potentially unfit or dangerous healthcare providers as part of the Medicare and Medicaid Patient and Program Protection Act of 1987 (DHHS \& HRSA, 2018). The NPDB began to collect data in 1990 when these laws were implemented (DHHS \& HRSA, 2018). The Health Insurance Portability and Accountability Act (HIPAA) of 1996 established the Health Integrity and Protection Data Bank (HIPDB), a tracking system to alert potential employers, licensing agencies, professional certification bodies and societies of the need to review a provider's history (DHHS \& HRSA, 2018). The Affordable Care Act (ACA) allowed the HIPDB to consolidate with the NPDB, and the databanks merged in 2013 to create the current NPDB (DHHS \& HRSA, 2018). The NPDB requires by law the reporting of physicians and dentists who have disciplinary action taken on their professional license, malpractice judgments, and/or hospital privileges or professional society adverse actions (DHHS \& HRSA, 2018). Any licensure action, including disciplinary action stemming from a 
substance use disorder or impairment of a practitioner taken by a state licensing authority are reportable to the NPDB by law within 30 days of action (DHHS \& HRSA, 2018).

Although nurses are not a required profession to be reported by HIPAA or the ACA, there are other laws that enforce the reporting of nurses to the NPDB. The National Council of State Boards of Nursing (NCSBN) acts as the repository for all nursing licensure discipline for boards of nursing throughout the United States (NCSBN, 2017). Disciplinary data pertaining to nurses (registered nurse [RN] and licensed practical nurse [LPN]) is collected via NURSYS, a database of licensure information used by state boards of nursing (NCSBN, 2017). NURSYS serves as the reporting agent to NPDB for the profession of nursing (NCSBN, 2017). States party to both the original Nurse License Compact (NLC) and the Enhanced Nurse License Compact (eNLC) are required by law to report any adverse licensure action to NURSYS to protect the public by reducing stateto state mobility of disciplined and potentially dangerous nurses (NCSBN, 2017). All data pertaining to nurse licensure discipline, both registered nurses $(\mathrm{RN})$ and licensed practical nurses (LPN) in the NPDB within the nurse licensure compact are reliably reported to NPDB by way of NURSYS. The states party to the original NLC will be used for this data analysis, as the implementation of the eNLC was not until January 19, 2018 (NCSBN, 2017). Pharmacists with disciplinary action are reported directly to the NPDB by their respective state board of pharmacy.

\section{Participants}

This secondary data analysis is IRB exempt, considered not human subjects research. The data used was previously collected and reported by law. The study presents no potential harm to any participants. The NPDB provides de-identified data in the public 
use data, so there is no potential for identification or harm to a professional reputation or confidentiality. Further, any formal disciplinary action taken on a licensee is considered public record. The researcher has agreed to the terms and conditions set forth by the NPDB public use data file.

\section{Sampling Methods}

The study sample is dictated by the number of licensed physicians, nurses, and pharmacists disciplined by their respective state boards based on statutory violations related to SUD. The sample for the study is also influenced by states required to report nurses to the NPDB. The total sample of licensed healthcare professionals with SUDrelated disciplinary action used in this data analysis is 17,489 . This includes 1604 physicians (including residents), 15,573 nurses (10,477 RN and 5101 LPN), and 41 pharmacists (including interns). The total number of licensed nurses (RN and LPN) in the United States is approximately 3.9 million (NCSBN, 2018). The total number of physicians is 953,695 and pharmacists 309,330 (Bureau of Labor Statistics, 2016; Young, Chaudhry, Pei, Arnhard, Dugan, \& Snyder, 2017). Nurses make up almost $80 \%$ of the healthcare workforce, physicians $15 \%$ and pharmacists $5 \%$. In this sample nurses make up $90 \%$ of the study population, $9 \%$ are physician, and $1 \%$ are pharmacists. The study sample from 24 states is similar to the proportion of the total workforce population.

It is difficult to identify the appropriate sample size to generalize to the population, as it is unknown the exact prevalence of SUD in the healthcare professions (Baldisseri, 2007). The study sample does not include licensees identified with SUD that have been or are currently enrolled in confidential alternative to discipline programs that are not disciplined upon successful completion of their program. Another factor that has 
the potential to impact the sample is a jurisdiction that may underreport licensure discipline or code the disciplinary action as "other". All potential cases that meet the inclusion criteria from the three professions are included in the study. The inclusion of all possible cases meeting study criteria renders a large sample of disciplined licenses from 24 states over 10 years using all potential SUD-related grounds for discipline.

\section{Variables}

The NPDB provides a de-identified public use data file download for Statistical Package for Social Sciences [SPSS], (2013). The NPDB Public Use Data File houses all licensure and malpractice adverse action data in 55 variables (DHHS \& HRSA, 2018). The public use data file was obtained with permission from the United States Department of Health and Human Services. The researcher obtained permission to download the public SPSS version of the databank. The variables in the NPDB contain demographic data ranging from information about the practitioner from licensure type, graduation year, and state of licensure to information pertaining to various types of disciplinary action and malpractice information, among many others. Refer to Appendix A for full list of variables contained in the public use data file of the NBDB (DHHS \& HRSA, 2018). For the purposes of this study, the variables from the databank that are used for data analysis pertain to adverse licensure action based on SUD in four licensure types. The variables from the NPDB public use file (see Appendix A) selected for this secondary data analysis include: licensure type (LICNFELD), state of licensure (LICNSTAT), adverse outcomes (AACLASS1- AACLASS5), basis for action (BASISCD1-BASISCD5), and year the action was taken (AAYEAR). 


\section{Inclusion and Exclusion Criteria Among Dataset Variables}

Independent variable: Type of licensure. The independent variable in this study is the type of licensure of the healthcare professional. Four licensed healthcare professions are compared in this study: medicine, nursing (both registered nurse and licensed practical nurse), and pharmacy. Practitioner discipline is entered into the databank with codes identifying their respective licensure types (Table 4.2). The NPDB data set is recoded to include only these four licensure types, excluding all other professions for which data is reported (Table 4.2). Allopathic physicians (MD), medical residents, osteopathic physician (DO), and osteopathic residents were combined to form "medicine." Each medical professional is recoded to "1" in SPSS from the original code used for the specific profession types. This combines the four physician types to one category for data analysis. Pharmacists and pharmacy interns are combined to "pharmacy." This is done by changing the original SPSS codes to a " 2 " to represent pharmacy.

Registered nurses (RN), are coded into one category and licensed practical nurses (LPN) are coded to their own respective category for data analysis. Advanced practice nurses including Certified Registered Nurse Anesthetists (APRN-CRNA), Nurse Practitioners (APRN—NP), Clinical Nurse Specialist (APRN-CNS) and Certified Nurse Midwives (APRN-CNM) are not included as nursing licensure types in this study. All Advanced Practice nurses are required to have a current active Registered Nurse license as part of the licensure requirements for APRNs in each state. If APRNs were included, each disciplined advanced practice licensee may potentially be disciplined twice as there are two licenses to discipline ( $\mathrm{RN}$ and $\mathrm{APRN})$. The licensure actions taken on one 
licensee with two separate licenses would be separately reported to NURSYS and the NPDB for the respective APRN and RN licenses. Excluding these advanced practice nursing license types prevents possible duplication of case records in data analysis by using both RN and APRN. The same person may be disciplined twice for the same violations of the law. After recoding the inclusion licensure types, all other professions are coded as " 0 " in the licensure type (LICNFELD) variable in SPSS, excluding all other professions from data analysis.

\section{Table 4.1 Licensure Types in Dataset}

\section{LICNFELD}

Allopathic Physician (MD)

Osteopathic Physician (DO)

Allopathic Physician Resident

Osteopathic Physician Resident

Pharmacist

Pharmacy Intern

Registered Nurse (RN)

Licensed Practical Nurse (LPN)
NPDB Code

10

20

15

25

5

55

100

140
New Code

$1=$ Medicine

$1=$ Medicine

$1=$ Medicine

$1=$ Medicine

$2=$ Pharmacy

$2=$ Pharmacy

$3=\mathrm{RN}$

$4=\mathrm{LPN}$

Dependent variable: Disciplinary action (Adverse outcome). This analysis compares the disciplinary action or adverse outcomes taken on professional licensees with violations pertaining to SUD among four professions. The dependent variable in this study is the type of disciplinary action taken on the licenses of healthcare professionals with SUD. Disciplinary outcome is represented in the NPDB public use data file as AACLASS1-AACLASS5. In the NPDB AALCLASS codes stand for adverse action classification. The types of disciplinary action that can be taken based on a violation of law following due process are similar across the professions and licensure jurisdictions; there is no effect on data from state to state or profession to profession. Potential disciplinary action consists of: censure or reprimand, probation, suspension, revocation, 
voluntary surrender, limitation, monetary fines, negative action, and other. These sanctions, like criminal or civil law can range from punitive and severe to lenient.

NPDB data representing adverse action or the disciplinary outcome are housed in five separate data variable columns (DHHS \& HRSA, 2018). This data is labeled in the database as AACLASS1, AACLASS2, AACLASS3, AACLASS4, and AACLASS5 (DHHS \& HRSA, 2018). All five columns house the same adverse licensure action codes. The NPDB houses all types of action taken on a licensee including civil court dispositions related to malpractice, professional society action or hospital privilege action, as well as Medicare or Medicaid exclusion actions taken by the Office of the Inspector General or DHHS (DHHS \& HRSA, 2018). All action not taken by a professional licensure board will be excluded from the study. The licensure action codes will be recoded in SPSS to represent licensure action included or excluded from the study. Table 3.1 depicts the adverse action records to be used for inclusion in the study.

There are five variables containing adverse action (AACLASS1-AACLASS5) in the NPDB because of the possibility of multiple sanctions being taken on one licensee. Due to the case-by-case nature of licensure investigations and subsequent sanctions, there is an array of possible discipline that could be carried out on one licensee for one or multiple violations of the law. For example, a licensee may have a diagnosed SUD, and this was found by the licensee being convicted of a DUI, which is a misdemeanor offense related to the practice of the profession. The licensee may have already been on probation and the probation is extended and they are fined with a censure for a violation of the previous order on discipline. The censure, fine, and probation are three different types of discipline based on one violation of the law and must be entered separately as discipline 
into the NPDB. Each disciplinary action taken would be entered on one variable under the same licensee on the same date the action was taken. A licensee with one action would be entered under AACLASS1 and any further actions would be entered under AACLASS2, AACLASS3 up to five licensure sanctions. In the case of SUD disciplinary action, any sanctions taken on a licensee would be included in the study and all types of action were accounted for. Combining all sanctions taken from all five variables allows for data analysis and comparison of all sanctions taken on a licensee without exclusion or duplication of any discipline that may impact the results.

Licensure discipline exclusions. For the purposes of this secondary data analysis, the length of time attached to discipline was excluded. For some forms of discipline, such as probation, suspension, or revocation there are time frames, for example probation for three years or a suspension for six months. The length variable (AALENGTH) in the NPDB public use data file were excluded, as this variable has no bearing on the research question. The data from the denials of initial licensure or license reinstatement were also excluded from this particular study. Denial of licensure refers to an initial application for licensure or an application for reinstatement of a license to practice a profession in a jurisdiction. Denial is considered a form of discipline, and reported to the NPDB just as discipline on an active license for the purposes of public protection. Initial discipline happens during the application process using the same statutory grounds as disciplinary action taken on an active license. However, for the purposes of this study, only the discipline of actively licensed healthcare providers was explored. 


\section{Table 4.2. Disciplinary Action Dataset}

Adverse Action or Disciplinary Outcome

\section{AACLASS 1-5}

Revocation of license

Probation

Suspension or Emergency/Summary Suspension

Reprimand/Censure

Voluntary Surrender

Limitation or Restriction

Administrative or Monetary Fine

Publicly Available Negative Action

Other

\section{NPDB Code}

1110

1125

$1135,1138,1139$

1140

1145,1146

1147

1172,1173

1189

1199

\section{Descriptive Inclusion Dataset Variables}

Grounds for discipline. The professional license of the healthcare provider with SUD is disciplined based on the violations of administrative law. For the purposes of this study, only violations of statute related to SUD were included. The violations included in this study are specific to a provider who has been disciplined for SUD following administrative legal proceedings (Table 4.3). Any other basis for licensure action was excluded from the study. Inclusion of these violations, specific to SUD, allowed for the study to compare the disciplinary sanctions of the four licensure types related to SUD.

The grounds for discipline are also housed in five data columns in the NPDB public use data file (DHHS \& HRSA, 2018). Disciplinary action is reported by the NPDB in multiple variables because one licensee may be disciplined based on findings of multiple statutory violations at the same time (DHHS \& HRSA, 2018). Each case entry into the NPDB represents one disciplinary disposition for one licensee. If the disciplinary disposition is based on multiple infractions, each infraction is entered into the databank under the same licensee each in a separate column in the grounds for discipline columns BASISCD1 through BASISCD5 using the necessary number of columns to record each 
basis code for discipline (DHHS \& HRSA, 2018). If there was only one violation, the grounds for disciplinary action were entered into one column for basis (Table 4.3). For example, a licensee may have a diagnosis of SUD (coded as 01 in one BASISCD variable) and diverted a substance from their employer and was charged for this in the criminal courts (coded as 66 in a second BASISCD variable). In this case there are two violations related to SUD, but counting all violations in this study would be duplicative and would potentially impact the data analysis. For a licensee who was impaired by another health issue, practiced negligently and documented in a substandard way, none of the grounds for discipline would be related to SUD, and therefore were excluded from data analysis. If that same provider was impaired by substances (coded as F2 in one BASISCD SPSS variable) the sanction was be related to SUD and coded in one grounds for discipline variable and therefore were included in the data analysis. For the purposes of this study combining the five separate variables was important to eliminate any unnecessary duplication or omission of data related to SUD.

The NPDB public use data contained in BASISCD1-BASISCD5 were combined to contain all five variables in one new variable representing violations related to SUD (Table 4.2). Each of the five disciplinary action variables were recoded in SPSS to represent a "yes" or "no" variable. Recoding the variables identified those sanctions related to SUD as "yes" and all other data as the basis for discipline as "no" This recoding allowed for the identification of inclusion criteria in one variable to select cases for data analysis. 


\section{Table 4.3 Grounds for Disciplinary Action in Dataset}

\section{Inclusion Data for SUD}

NPDB codes

01

08

35

61

66

F2

$\mathrm{H} 1$

H6

\section{BASISCD1- BASISCD5}

Alcohol or other substance abuse

Narcotics Violation

Drug screening violation

Felony conviction related to controlled substance violation

Conviction related to controlled substances

Unable to practice safely by reason of alcohol or other substance abuse Narcotics violation or violation of drug statutes

Diversion of controlled substance

State of licensure. Data for this study includes disciplinary action reported to the NPDB from 24 states. The states included in the study are: Arizona, Arkansas, Colorado, Delaware, Idaho, Iowa, Kentucky, Maine, Maryland, Mississippi, Missouri, Nebraska, New Hampshire, New Mexico, North Carolina, North Dakota, Rhode Island, South Carolina, South Dakota, Tennessee, Texas, Utah, Virginia, and Wisconsin. These states are included because they are a part of the original Nurse Licensure Compact (NLC), refer to Appendix B. Montana is excluded from data analysis, as they entered into the original nurse licensure compact effective October 2015 (NCSBN, 2015). In order to compare nursing with other professions, it is essential to use only NLC states, as they are required by law to report to NURSYS. Article VI (see Appendix C) of the original compact legislation, enacted in each state as part of the NLC requires the establishment of a reporting databank for public protection from potentially dangerous practice by sharing disciplinary information (NCSBN, 2016). NURSYS is the reporting agent for nursing to the NPDB, so the data reported from the original compact states is reliable data, reported by law. 
States not party to the NLC cannot be assumed to be reliable reporters, as there is no legal requirement to report adverse licensure action to NURSYS or NPDB. A number of states joined the enhanced NLC (eNLC), a new set of laws updating the interstate licensure compact for nursing practice, implemented on January 19, 2018. The enhanced nurse licensure compact contains improved licensure requirements for interstate practice, but maintains the requirements for states to report disciplinary action to NURSYS and the NPDB (NCSBN, 2015). However, because many of these states joined the compact in the last three years, they were excluded to ensure data was reliable with reporting to the NPDB for the last eight years providing sufficient case numbers for data analysis. Discipline could be taken on the multistate privilege to practice by all states party to the compact for dangerous, incompetent, or impaired practice, however, discipline taken only in the nurse's primary state of residence is used for this study. Disciplinary action taken by a compact state is reported to NURSYS and eventually the state of residence, will have authority to discipline the license (NCSBN, 2015). A state taking action on the privilege to practice in the compact would be duplicate discipline, as all action is taken on the same grounds. Another code used by NPDB as grounds for discipline are sanctions taken on a multistate privilege to practice (DHHS \& HRSA, 2018). This code was excluded from data analysis to prevent duplication of records.

Year. The NPDB houses many years of disciplinary data. For the purpose of this study ten years of past data from 2007 through 2017 was used. Years previous to these inclusion years will be recoded as exclusion data from the data column AAYEAR in NPDB prior to data analysis. AAYEAR represents the year the adverse action was taken 
on the licensee. To include the previous ten years and exclude all other records, this was simply recoded in SPSS and used as a parameter for data analysis.

Alternative to discipline. Some licensure jurisdictions have alternative to discipline programs for healthcare professionals with SUD, which provide for treatment and monitoring without licensure discipline (NCSBN, 2011). Healthcare professionals who successfully comply with the contract of the alternative program do not have disciplinary action. This study only compares healthcare professionals with formal licensure discipline, who have been entered into the NPDB. It does not include those enrolled in alternative to discipline programs, which are confidential. No licensees that had enrolled in or had successfully completed an alternative program are included in the NPDB public use data, as they are not reported to the NPDB. Only the licensees disciplined based on statutory grounds were included in this study.

\section{Procedures}

Licensure discipline is evaluated by isolating and recoding study associated variables from the NPDB public data use file using SPSS. The inclusion variables were first recoded to select the appropriate data to be analyzed from the variables. First, the descriptive inclusion variables basis for action, year action is taken, and state of licensure were recoded in SPSS to include only the data used in the study.

State of licensure is coded as "LICNSTAT" in the NPDB public use data file. Data in this variable was changed by the SPSS function 'recode to different variable'. Inclusion states (Appendix B) were entered into the NPDB by their state postal code, considered the "Old value" by the NPDB. The "New Value" was entered as "1" for all states included in the study. In this function dialogue box, all 24 inclusion states were 
listed to equal " $1 . "$ All other values were coded as " 0 " using the "all else" function in SPSS (ELSE = "0"). The recode arranges inclusion data into a new variable, named "state," all 24 states were then identified as " 1 " and any excluded were " 0 " for ease of data analysis.

Year of adverse action, "AAYEAR" is also recoded to include the years 20072017 in the data analysis and exclude all other years recorded in the NPDB. This is accomplished by again utilizing the function in SPSS of 'recode to different variable.' Under the old variable values the range of 2007-2017 was entered in the dialogue box with a new variable value entered as "1". All other years excluded from data analysis are recoded using the "all other" option in 'recode to different variable' under 'old value' and identifying the "new value' as " 0 " (else=0). Recoding left the years 2007-2017 as " $1=$ yes" to include and all other years as " 0 " to exclude from analysis. The new variable was named "year" for analysis.

The next variable to be recoded was the licensure type or LICNFELD in order to group the codes to be used for nurses, physicians, and pharmacists (Table 4.2). This variable was recoded into a new variable the same way, using the recode to new variable function in SPSS. The new variable was named license, with old values representing each profession. MD, DO, and MD and DO residents were combined into " 1 " to represent medicine. Pharmacists and pharmacy interns were combined from their old value codes to "2" representing pharmacy. Finally, RN and LPN licensure codes in the data set were changed to a new value of " 3 " and " 4 ". The value of " 3 " represents the RNs and the value of " 4 " represents the LPNs. All other values in the LICNFELD were recoded as "0" (else $=0$ ) using the 'all other values' function in the dialogue box, so that coding the data 
excluded all other professions from data analysis. This variable was named "License" and functioned to group the data into profession type for data analysis and comparison.

The NPDB reports adverse outcomes on each licensee in five separate variables, as a single licensee may be disciplined based on multiple statutory violations or just one single violation. The five variables housing the basis for action were combined to one new variable, in effect making one variable to identify cases of discipline related to substance use disorder. Basis for action, BASISCD1 was recoded by selecting the SPSS function 'recode to new variable' and entering all codes related to SUD (Table 4.3) as the old values, recoding each to " 1 " in the "new value' box. All other values were recoded as " 0 " by selecting the 'all other' function as the 'old value' and entering the new value as "else $=0$ ". This same procedure was repeated with all basis for action variables: BASISCD2, BASISCD3, BASISCD4, and BASISCD5. The new variables were named SUD1-SUD5 corresponding to the original BASISCD column. To combine all five variables and ensure no licensee that may be disciplined based on two or more different grounds related to SUD so only to be counted once, the variables had to be recoded again. The data was recoded to a new variable "SUD" by using the 'compute variable' function and adding the variables together. This was entered into SPSS as: $($ SUD1 $)+($ SUD2) $+($ SUD3)+(SUD4)+SUD5). This added together any disciplinary action related to SUD housed in any of the five variables, with "0" meaning no basis for disciplinary action related to SUD in this case and was excluded from the data analysis. A minimum of "1" means one SUD-related action existed for a licensee to a max of "5" meaning multiple grounds were present for SUD-related disciplinary action entered into the NPDB. The summed new variable was then turned into another variable to be used 
for data analysis by recoding the new variable "SUDPOS" using the recode function with the old value greater than or equal to "1" $=" 1 "$ and all else $=" 0 "$. The changes to this variable were renamed SUDPOS= "1" tells SPSS the inclusionary data for the codes of discipline are those related to SUD.

The dependent variable, disciplinary action is also housed in five variables as licensees may incur multiple sanctions based on one or more grounds for disciplinary action. Licensure discipline related to SUD could be entered in any of the five variables AACLASS1, AACLASS2, AACLASS3, AACLASS4, or AACLASS5 or a combination of two or more. To ensure the necessary data was used for analysis but not duplicated, all types of discipline were recoded for each disciplinary variable. There were nine types of licensure discipline to be included in the study to compare across professions: revocation, probation, suspension, censure, voluntary surrender, limitation or restriction, administrative penalty or fine, generic negative action, and 'other' (Table 4.1). The codes entered into the NPDB for discipline in all five variables were the same. The data in the five variables for licensure discipline were combined and grouped to include all the disciplinary data to be analyzed using the 'recode variable' function in SPSS. Each AACLASS variable was recoded and grouped into types of discipline for comparison by selecting the 'recode to new variable function' and making the new variables reflect disciplinary outcomes. First, the variable AACLASS1 was recoded with the new variable name 'revocation' numbered corresponding to each initial variable they represent (AACLASS1-AACLASS5). The NPDB code for revocation was entered as the 'old value' and the new value was changed to " 1 ". The 'all else' function was used apply a new code of " 0 " to all other licensure discipline. This new variable then contained a " 1 " 
to indicate only those licensees with revocation as discipline, "0" represented all other disciplinary action excluded from chi-square data analysis. The same recode functions were carried out with the same disciplinary code for revocation with all four variables AACLASS2 through AACLASS5, rendering five new variables: revocation1, revocation2, revocation3, revocation4, and revocation5. When all five variables were recoded, the 'compute variable' function was used to add all five new variables revocation1-revocation5 together, recoded into one new revocation variable. The new variable contained only revocations taken on a licensee, combining all of the data in the five initial NPDB variables, and sorting to one type of discipline. Each new discipline variable identifies the specific discipline taken on one licensee making this a yes or no variable required for chi-square data comparison in this study. The same steps were taken with each type of disciplinary action to recode each type of discipline (Table 4.1) to separate them for data analysis and comparison. AACLASS1-5 was recoded for each type of disciplinary action: revocation, probation, suspension, censure, voluntary surrender, limitation, monetary fines, and "other." The final product were the new variables containing the data to analyze the dependent variable.

\section{Data Analysis}

Prior to data analysis, inclusion data for the variables state, year, and grounds for discipline were filtered using the SPSS function 'select cases.' The 'select cases if' function was chosen in SPSS and the inclusion criteria were entered as: (state $>=1$ ) \& (year $>=1) \&($ SUDpos $>=1)$. This filtered out cases outside the date range, out of the licensure compact states, and the cases not related to SUD. A data report was run after the 
data were filtered to identify any missing data. There were no missing data identified in any of the variables included in the data analysis.

The recoded data used for the study were evaluated using chi-square to compare disciplinary action among the licensed professions (license type). Chi-square is used for statistical analysis and an appropriate statistical test, as the data are nominal, there are three groups (license type) to compare independent of one another, and in that each disciplined licensee contributes data to only one cell. Each group to be compared (license type) had different sample sizes, and the overall sample was large (McHugh, 2013). Each type of licensure discipline was compared independently among the three types of licensure using separate chi-square tests. There were nine separate chi-square tests for disciplinary outcomes run to compare each type of disciplinary action among physicians, pharmacists, and nurses. Data was interpreted for statistical significance at $\alpha=0.05$ (Kellar \& Kelvin, 2015).

Statistical analysis was completed by selecting the 'analyze' option in SPSS, then selecting the 'crosstabs' function. The recoded and combined disciplinary action was entered into the row and 'license' representing the three recoded professions was entered into the column. chi-square was selected, as well as percentages prior to running the test in SPSS. The statistical output was then placed into a table format for data analysis (Appendix D). 


\section{CHAPTER 5}

\section{RESULTS}

The total sample of 17,488 licensed healthcare professionals disciplined based on a SUD violation were all contained in the following secondary data analysis for each type of licensure discipline. There was a total sample of 10,742 RNs, 5101 LPNs, 1604 MDs, and 41 Pharmacists disciplined in 24 states over 10 years for SUD-related sanctions. In each chi-square test there were no missing data found. There were statistically significant differences found among the professions with revocation, probation, censure, voluntary surrender, limitation, negative action, monetary fines, and 'other.' There were no statistically significant differences found between the professions with licensure suspension in this study.

\section{Punitive Versus Less-Punitive Discipline}

While any discipline taken on a professional license can affect the professional's reputation or career, some forms of discipline are more severe than others. The punitive nature of the disciplinary action is compared in this study using the same reason (basis) for discipline to be taken. Revocation and suspension are considered the harshest form of disciplinary action as both interfere with the ability to practice a profession altogether for a period of time (NCSBN, 2018). Probation is a difficult sanction, but much less punitive. The licensee on probation must follow strict terms and conditions set by the professional board to practice their profession (NCSBN, 2018). Voluntary surrender is when the licensee chooses to forfeit their licensure. This is considered discipline, as the regulatory agencies do not want dangerous practitioners to move to another jurisdiction without any record of punishment. If a licensee is able to give their license up without discipline they 
may reinstate the license in another state and resume practice. Voluntary surrender is similar to revocation but of the licensee's choosing. For the purposes of this study, voluntary surrender is considered more punitive as the licensee feels this is their only choice, and the profession loses a practitioner that could potentially rehabilitate. Finally, monetary fines, while better than revocation of a license is a financial hit and still considered formal disciplinary action.

A censure or warning is considered much less harsh and the licensee is still able to make a living practicing their chosen profession. Although censure is formal discipline and must be reported to the databanks, it does not impede practice or place any restrictions on the provision of healthcare services (NCSBN, 2018). Disciplinary action may be intended to protect the public, but may be seen as punishment rather than protecting patients as the provider recovers. Less punitive forms of punishment also include limitation, negative action, and 'other'. Limitation simply places one or more stipulations on the practice of the licensee. A limitation can be any number of things, not explored in this data analysis. However, a limitation allows the practitioner to practice as long as they follow their guidelines. Negative action and other are both considered less punitive, as this is a vague way of reporting a disciplinary outcome, essentially not reporting any other form of discipline. This type of reporting may, in essence, protect the licensee from the public identifying other discipline such as probation or suspension. In this secondary data analysis, each type of disciplinary outcome is compared profession to profession. There are no considerations taken for length of terms or the circumstances behind any disciplinary action or the differences between jurisdictions. 


\section{Punitive Disciplinary Action}

Revocation. The most severe form of disciplinary action was found to be significant $(p=0.000)$ between the professions, accounting for $11.4 \%$ of total licensure discipline. LPN's licenses are revoked at a much higher rate than both registered nurse and medicine $(\mathrm{p}=0.000)$. Revocations accounted for $15.6 \%$ of total discipline for LPNs and only $10.2 \%$ for RNs. Twenty two percent of pharmacy licensure discipline related to SUD was revocation. Having an SUD with a medical license has much lower probability of having license revocation. Medical licensees with SUD were expected to have 182.2 revocations and only 85 actually occurred, whereas 579.3 LPNs were expected to have a revocation with SUD and 797 actually were revoked. There are large differences between expected and actual counts in the chi-square analysis in these two licensure types, one significantly more and one significantly less, These numbers point to LPNs having a much greater chance to have their license revoked related to SUD than those in the medical profession. Nursing (RN and LPN) accounted for over $90 \%$ of total licensure revocations in this study.

Table 5.1 Chi-Square Results of Revocation

\begin{tabular}{l|l|l|l|l|l|l}
\hline & MD & RX & RN & LPN & Sig & Total \\
\hline Revocation & $85 / 182.2$ & $\mathbf{9 / 4 . 7}$ & $1095 / 1219.9$ & $\mathbf{7 9 7 / 5 7 9 . 3}$ & $\begin{array}{l}\text { YES } \\
\mathrm{p}=.000\end{array}$ & $\begin{array}{l}11.4 \% \text { of total } \\
\text { discipline }\end{array}$ \\
\cline { 2 - 3 } & $\begin{array}{l}5.3 \% \text { of } \\
\text { MD } \\
\text { discipline }\end{array}$ & $\begin{array}{l}\text { 22\% of } \\
\text { RX } \\
\text { discipline }\end{array}$ & $\begin{array}{l}\text { 10.2\% of } \\
\text { RN total } \\
\text { discipline }\end{array}$ & $\begin{array}{l}\text { 15.6\% of } \\
\text { LPN total } \\
\text { discipline }\end{array}$ & & \\
\hline
\end{tabular}

Probation. Probation is less punitive than revocation or suspension, but may make it difficult for a licensee to practice their profession. Probation provides for strict guidelines, strict supervision, and strict monitoring in order to provide care to patients 
(NCSBN, 2018). Probation accounted for $24.5 \%$ of total licensure discipline related to SUD in this study. The RN and pharmacist are more likely to be placed on probation for substance-related offenses than are physicians. LPNs have less probability than the RN to be placed on probation for a SUD-related offense. While probation is better than revocation, this is still a more significant penalty than fines or a censure. Probation is $26.6 \%$ of the total $\mathrm{RN}$ discipline and $34.1 \%$ of total pharmacy discipline compared to $12.3 \%$ of total SUD-related physician disciplinary action.

MDs were expected to have 393.2 licenses placed on probation and only 197 actually were reported in this study. This is a much greater difference than the RN and LPN. The ratio between expected and actual is slim in both nursing licensure types. Therefore the statistical significance may be related more to the medical profession ratio. There may be less correlation among nursing with lower ratios. While RNs are more likely to have probation, the ratio was small: 2633.3 expected and 2859 actual, LPN was 1217 actual and 1250.5 expected.

Table 5.2 Chi-Square Results of Probation

\begin{tabular}{|c|c|c|c|c|c|c|}
\hline & MD & $\mathrm{RX}$ & RN & LPN & Sig & Total \\
\hline \multirow[t]{2}{*}{ Probation } & $197 / 393.2$ & $14 / 10.1$ & $2859 / 2633.3$ & $1217 / 1250.5$ & $\begin{array}{l}\text { YES } \\
n=\end{array}$ & $\begin{array}{l}24.5 \% \text { of total } \\
\text { discinline }\end{array}$ \\
\hline & $\begin{array}{l}12.3 \% \text { of } \\
\text { MD } \\
\text { discipline }\end{array}$ & $\begin{array}{l}34.1 \% \text { of } \\
\mathrm{RX} \\
\text { discipline }\end{array}$ & $\begin{array}{l}26.6 \% \text { of } \\
\text { RN } \\
\text { discipline }\end{array}$ & $\begin{array}{l}\overline{23.9 \% \text { of }} \\
\text { LPN } \\
\text { discipline }\end{array}$ & 0.000 & \\
\hline
\end{tabular}

Suspension. Suspension is another form of punitive discipline, essentially halting a licensee from practicing for a designated period of time. No significant differences across professions are found with suspension. This is the only type of disciplinary outcome in this data analysis that was not statistically significant, with $p=0.243$. 
Suspensions accounted for $28.6 \%$ of total licensure discipline. There is no greater chance for suspension from one profession to the next.

Table 5.3 Chi-Square Results of Suspension

\begin{tabular}{|c|c|c|c|c|c|c|}
\hline & MD & $\mathrm{RX}$ & RN & LPN & Sig & Total \\
\hline \multirow[t]{2}{*}{ Suspension } & $451 / 458$ & $7 / 11.7$ & $3051 / 3072.5$ & $1493 / 1459$ & $\begin{array}{l}\text { NO } \\
p=243\end{array}$ & $\begin{array}{l}28.6 \% \text { of total } \\
\text { discipline }\end{array}$ \\
\hline & $\begin{array}{l}28.1 \% \text { of } \\
\text { MD } \\
\text { discipline }\end{array}$ & $\begin{array}{l}17.1 \% \text { of } \\
\mathrm{RX} \\
\text { discipline }\end{array}$ & $\begin{array}{l}28.4 \% \text { of } \\
\text { RN } \\
\text { discipline }\end{array}$ & $\begin{array}{l}29.3 \% \text { of } \\
\text { LPN } \\
\text { discipline }\end{array}$ & & \\
\hline
\end{tabular}

Voluntary Surrender. Voluntary surrender is statistically significant between professions, $p=0.000$. Registered Nurses and pharmacists are found to have a higher probability of surrendering a license in lieu of disciplinary action. The voluntary surrender is considered punitive, as this is a lesser form of revocation and still claims a license to practice the profession as well as the professional's identity (NCSBN, 2018). Voluntary surrender accounts for $18.6 \%$ of $\mathrm{RN}$ discipline and $22 \%$ of pharmacy discipline. Voluntary surrender accounts for $17.5 \%$ of total disciplinary action in this study. Although this type of disciplinary action was statistically significant there is possibly less correlation between discipline and the professions as the ratios between the expected and actual are slimmer than other forms of discipline.

Table 5.4 Chi-Square Results of Voluntary Surrender

\begin{tabular}{|c|c|c|c|c|c|c|}
\hline & $\mathrm{MD}$ & $\mathrm{RX}$ & $\mathrm{RN}$ & LPN & Sig & Total \\
\hline \multirow[t]{2}{*}{$\begin{array}{l}\text { Voluntary } \\
\text { Surrender }\end{array}$} & $205 / 281.4$ & $9 / 7.2$ & $2002 / 1884.5$ & $852 / 894$ & $\begin{array}{l}\text { YES } \\
p=\end{array}$ & $17.5 \%$ of total \\
\hline & $\begin{array}{l}12.8 \% \text { of } \\
\text { MD } \\
\text { discipline }\end{array}$ & $\begin{array}{l}22 \% \text { of } \\
\mathrm{RX} \\
\text { discipline }\end{array}$ & $\begin{array}{l}18.6 \% \text { of } \\
\text { RN } \\
\text { discipline }\end{array}$ & $\begin{array}{l}16.7 \% \text { of } \\
\text { LPN } \\
\text { discipline }\end{array}$ & 0.000 & \\
\hline
\end{tabular}

Monetary Fines. Licensed Practical Nurses with SUD have a statistically significant difference in monetary fines as disciplinary action related to $\mathrm{SUD}, p=0.000$. 
LPNs have a higher probability of being fined than their RN colleagues or those with medical or pharmacy licenses. Monetary fines, or administrative penalties accounted for $14.9 \%$ of SUD-related discipline taken on LPNs which is a significant percentage considering fines make up $11 \%$ of total SUD-related discipline. There is a large ratio between the expected count of 561.5 and the actual 762 LPNs fined in the study. This gap may account for much of the significance, as the RN and pharmacists had less difference in expected and actual ratios. Physicians were less likely to be fined with an expected count of 176.6 and 85 were actually fined.

Table 5.5 Chi-Square Results of Monetary Fines

\begin{tabular}{|c|c|c|c|c|c|c|}
\hline & MD & $\mathrm{RX}$ & $\mathrm{RN}$ & LPN & Sig & Total \\
\hline \multirow{2}{*}{$\begin{array}{l}\text { Monetary } \\
\text { Fines }\end{array}$} & $85 / 176.6$ & $3 / 4.5$ & $1075 / 1182.4$ & $762 / 561.5$ & \multirow{2}{*}{$\begin{array}{l}\text { YES } \\
p= \\
0.000\end{array}$} & \multirow[t]{2}{*}{$11 \%$ of total } \\
\hline & $\begin{array}{l}5.3 \% \text { of } \\
\mathrm{MD} \\
\text { discipline }\end{array}$ & $\begin{array}{l}7.3 \% \text { of } \\
\text { RX } \\
\text { discipline }\end{array}$ & $\begin{array}{l}10 \% \text { of } \mathrm{RN} \\
\text { discipline }\end{array}$ & $\begin{array}{l}14.9 \% \text { of } \\
\text { LPN } \\
\text { discipline }\end{array}$ & & \\
\hline
\end{tabular}

\section{Less Punitive Disciplinary Action}

Censure. Censure is a less severe form of discipline, a warning recorded as disciplinary action. A censure does not restrict a professional's practice. A statistically significant difference was found in SUD-related censures among the three professions, $p=0.000$. MDs are more likely than other professions to be censured for a SUD-related offense. Censure makes up $18.5 \%$ of total SUD-related discipline for physicians, and accounts for less than $6 \%$ of total discipline in the other professions sampled. For physicians, the expected number of censures from the analysis is 109.3 and the actual number is 298 . This is a large difference in the ratio, as is the case with the other 
professions. This data supports the thought physicians are punished less punitively than other professions.

Table 5.6 Chi-Square Results of Censure

\begin{tabular}{l|l|l|l|l|l|l}
\hline & MD & RX & RN & LPN & Sig & Total \\
\hline Censure & $\mathbf{2 9 8 / 1 0 9 . 3}$ & $0 / 2.8$ & $620 / 732.2$ & $276 / 347.7$ & $\begin{array}{l}\text { YES } \\
\mathrm{p}=.000\end{array}$ & $\begin{array}{l}11.4 \% \text { of total } \\
\text { SUD discipline }\end{array}$ \\
\cline { 2 - 3 } & $\begin{array}{l}\text { 18.5\% of } \\
\text { MD } \\
\text { discipline }\end{array}$ & $\begin{array}{l}\text { 0\% of RX } \\
\text { discipline }\end{array}$ & $\begin{array}{l}5.8 \% \text { of RN } \\
\text { discipline }\end{array}$ & $\begin{array}{l}5.4 \% \text { of } \\
\begin{array}{l}\text { Nurse } \\
\text { discipline }\end{array}\end{array}$ & & \\
\hline
\end{tabular}

Limitation. A limitation is a practice stipulation imposed by the regulatory body on the licensee. It is usually related to the violation and seeks to limit practice to protect the public, yet allow the practitioner to practice their profession. There is a statistical significance among the professions with limitations, $p=0.000$. Like censure, physicians are more likely to have a limitation placed on their license. $15.3 \%$ of licensure discipline taken on MDs is a limitation of some form. Limitations account for only $6.6 \%$ of total discipline in this secondary data analysis. The other professions have less probability of having a limitation placed on their practice. The ratios between expected counts and actual counts in the chi-square analysis with limitation all have wide ratios. This tells of the sensitivity of the differences between the professions, namely medicine and the other three professions.

Table 5.7 Chi-Square Results of Limitation

\begin{tabular}{l|l|l|l|l|l|l}
\hline & MD & RX & RN & LPN & Sig & Total \\
\hline Limitation & $\mathbf{2 4 6 / 1 0 5 . 9}$ & $1 / 2.7$ & $679 / 709.5$ & $229 / 336$ & $\begin{array}{l}\text { YES } \\
\mathrm{p}=\end{array}$ & $6.6 \%$ of total \\
& $\begin{array}{llll}25.3 \% \text { of } \\
\text { MD } \\
\text { discipline }\end{array}$ & $\begin{array}{l}2.4 \% \text { of } \\
\text { RX } \\
\text { discipline }\end{array}$ & $\begin{array}{l}\text { 6.3\% of RN } \\
\text { discipline }\end{array}$ & $\begin{array}{l}\text { 4.5\% of LPN } \\
\text { discipline }\end{array}$ & 0.000 & \\
\hline
\end{tabular}


Other Discipline. "Other" is an unknown as far as disciplinary action. Depending on the regulatory body, this could be a way of disciplining a provider without disclosing too much about the violation in the NPDB. In this data analysis, there are significant differences among the professions, with $\mathrm{p}=0.005$ in the "other" discipline category. "Other" discipline accounted for $15.6 \%$ of total licensure discipline related to SUD. Physicians and LPNs had a higher probability of having "other" as a disciplinary outcome, but not by a large ratio. RNs have less probability of being disciplined by "other" also, but not a large margin.

Table 5.8 Chi-Square Results of Other Discipline

\begin{tabular}{|c|c|c|c|c|c|c|}
\hline & MD & $\mathrm{RX}$ & RN & LPN & Sig & Total \\
\hline \multirow[t]{2}{*}{ Other } & $278 / 249$ & $2 / 6.4$ & $1607 / 1672$ & $835 / 794$ & \multirow{2}{*}{$\begin{array}{l}\text { YES } \\
\mathrm{p}= \\
0.005\end{array}$} & \multirow[t]{2}{*}{$15.6 \%$ of tota } \\
\hline & $\begin{array}{l}1.6 \% \text { of } \\
\text { MD } \\
\text { discipline }\end{array}$ & $\begin{array}{l}4.9 \% \text { of } \\
\mathrm{RX} \\
\text { discipline }\end{array}$ & $\begin{array}{l}\overline{15 \% \text { of } \mathrm{RN}} \\
\text { discipline }\end{array}$ & $\begin{array}{l}16.5 \% \text { or } \\
\text { LPN } \\
\text { discipline }\end{array}$ & & \\
\hline
\end{tabular}

Negative action. Negative action is another type of disciplinary outcome that is vague. This tells the public discipline has been taken on a licensee, but does not elaborate what that is specifically. Negative action is linked to the same basis for SUD as all other forms of discipline. Negative action is found to have statistical significance $(p=0.000)$ among professions, although it makes up less than $1 \%$ of total disciplinary action in the sample. Physicians are more likely to be entered into the NPDB with "negative action" related to SUD than other professions. Physicians disciplined with negative action equal $1 \%$ of total physician discipline. This type of discipline had small numbers compared to the other disciplinary outcomes. The actual numbers compared to the expected numbers 
in the chi-square analysis are much higher for physicians and much lower for both types of nurses.

Table 5.9 Chi-Square Results of Negative Action

\begin{tabular}{|c|c|c|c|c|c|c|}
\hline & MD & RX & RN & LPN & Sig & Total \\
\hline \multirow{2}{*}{$\begin{array}{l}\text { Negative } \\
\text { action }\end{array}$} & $16 / 4.9$ & $0 / 0.1$ & $26 / 32.6$ & $11 / 15.5$ & YES & $0.3 \%$ of total \\
\hline & $\begin{array}{l}1 \% \text { of MD } \\
\text { discipline }\end{array}$ & $\begin{array}{l}0 \% \text { of } \mathrm{RX} \\
\text { discipline }\end{array}$ & $\begin{array}{l}0.2 \% \text { of all } \\
\mathrm{RN} \\
\text { discipline }\end{array}$ & $\begin{array}{l}0.2 \% \text { of all } \\
\text { LPN } \\
\text { discipline }\end{array}$ & 0.000 & \\
\hline
\end{tabular}

\section{Interpretation}

Despite similar estimated SUD rates and risk factors among physicians, nurses, and pharmacists, there are significant differences between SUD-related licensure sanctions among the professions in the sampled states. Severe sanctions, like revocation are found to be more common in nursing and pharmacy. Nurses were twice as likely to have their professional license revoked for SUD than their physician colleagues with SUD. Pharmacists are three times as likely to be placed on probation as physicians, and nurses are twice as likely as physicians to be placed on probation. Physicians were more likely to have less punitive discipline like censure or limitations. As for licensure suspension, there were no significant differences found among the professions. This was the only disciplinary outcome not found to have statistically significant differences among the professions.

The null hypothesis is rejected for all disciplinary action with the exception of suspension. The null hypothesis is rejected for revocation, probation, voluntary surrender, censure, monetary fines, limitations, negative action, and other: there are statistically significant differences among professions with SUD-related disciplinary action. The null 
hypothesis is accepted with suspension: there are no statistically significant differences among the professions with SUD-related suspension.

\section{Generalizability}

The study is a retrospective design using all available collected data that is available and meets inclusion criteria. The sample used for the data analysis is large and robust for good statistical analysis. The study sample also closely resembles the known populations of the various healthcare licensure types included in this study. The total sample of each profession is close to the estimated 6-14\% (Baldisseri, 2007; NCSBN, 2011). The study sample is comprised of 24 out of the 50 United States jurisdictions, $100 \%$ of the original nurse license compact. The results are based on data collected from the NPDB, as reported by law. Therefore the results could be generalized to the population. 


\section{CHAPTER 6}

\section{DISCUSSION}

Nurses report feeling they are punitively punished if they are found to have SUD (Darbro, 2005; Monroe \& Kenaga, 2011; Scimeca, 2008). This secondary data analysis of licensure discipline related to SUD supports this claim. There are significant areas of concern related to SUD: early identification and reporting, treatment, and adequate public protection, all affected by licensure discipline. The final disciplinary outcome affects how those in a profession approach these issues related to SUD.

\section{Stigma}

There is also significant stigma attached to the healthcare professional who has SUD; addiction is seen as a moral failing more than a treatable disease with higher stakes in the healthcare professional (Angres et al., 2012; Bryson, 2012). If nurses are punished more punitively, the fear of punishment has the potential to drive many nurses to continue to practice impaired, further placing patients at greater risk for harm. The theoretical framework for this study uses stigma as the reason there are such differences between the professions. Nurses do hold themselves to very high standards and should continue to do so. However, can the standards of the profession cause discipline related to SUD to be more punitive than necessary to protect the public? Medicine has high standards for the profession and disciplines with much less punitive measures. Pharmacy falls in between with both punitive and non-punitive punishment. This study provides evidence of differences among professions with SUD-related licensure discipline. There is also evidence for the need to further evaluate SUD-related discipline for the purposes 
of public safety versus the potential for ongoing harm caused by those attempting to avoid disciplinary action.

\section{Intervention and Treatment}

Previous research has found nurses who identify with punitive punishment related to SUD are less likely to enter treatment (Monroe, Kenaga, Dietrich, Carter, \& Cowan, 2013; NCSBN, 2011). The nurse suffering from SUD may continue to work very hard to hide their addiction for fear of loss of livelihood and their identity as a nurse (Lillibridge, Cox, \& Cross, 2002; Scimeca, 2008). Research supports early identification and assistance allows the healthcare professional the opportunity to recover. Getting the professional help becomes problematic in the face of punitive punishment. If a nurse or other healthcare professional perceives they will have their license revoked once they seek help or are found out by others, they may continue to hide their problem (Lillibridge et al., 2002; Merlo, Cummings, \& Cottler, 2003; Scimeca, 2008).

Patient safety is at risk when any healthcare professional goes to work impaired by a substance. Compounding the problem, colleagues in a position to identify impairment and provide support through early intervention and assistance are less likely to report for fear of causing professional harm (Bettinardi-Angres \& Bologeorges, 2011; DesRoches, Rao, Fromson, Birnbaum, Iezzoni, Vogeli, \& Campbell, 2010; Monroe \& Kenaga, 2011). There is a fear of reporting and labeling a colleague as a drug addict stemming from a lack of education and training for most healthcare professionals related to SUD (Baldisseri, 2007; Bettinardi-Angres \& Bologeorges, 2011). Fear of reporting may lead to a culture of silence especially with physicians or those in positions of power. The idea of falsely labeling a co-worker with SUD leads to fear of job related retaliation 
(Baldisseri, 2007). Protection of physicians and the need to protect financial interests of healthcare delivery systems is also a very real issue (Baldisseri, 2007). Physicians tend to protect each other as well. Physicians identify they have a professional duty to report impairment, however, when faced with the situation do not report (DesRoches et al., 2010). The reasons physicians do not report is they feel someone else will take care of the problem and nothing will happen as a result of the report, which is confirmed by this study (DesRoches et al., 2010).

There are different perspectives from nurses when it comes to treatment related to SUD. Nurses in recovery identify loss of their nursing license and professional identity with entering a treatment program for a SUD (Lillibridge, Cox, \& Cross, 2002). There is a body of literature that identifies early intervention as necessary for both public protection and help of the nurse (Monroe, et al., 2013; NCSBN, 2011). However, this is not possible when nurses who are suffering from SUD identify they were able to practice the profession for long periods of time without detection (Dittman, 2008; Monroe \& Kenaga, 2011). The nurses who do want help identify they are fearful of the punitive repercussions (Monroe, \& Kenaga, 2011). This study provides support for these fears and future steps could be taken to identify ways to help nurses seek early and appropriate treatment (NCSBN, 2011).

There is evidence to support the nature of nursing discipline may drive nurses into hiding their problems for fear of the loss of their livelihood and professional identity (Darbro, 2008; NCSBN, 2011). This fear is supported in evidence provided by Monroe et al., finding a much higher prevalence of SUD being treated in alternative programs that are non-disciplinary in nature (2013). Approximately $75-90 \%$ of nursing regulatory 
action taken is related to SUD, so nurses are fully aware of the potential professional consequences of this disease (Darbro, 2008). The difference in the management of SUD with healthcare providers is evidenced by this study. Therefore, further research should evaluate the best way to manage SUD from a regulatory standpoint.

\section{Recovery}

The very same characteristics that make successful healthcare providers are those that aid in recovery from SUD. These Healthcare providers tend to be high-achieving, intelligent, goal oriented people and are more likely than the general public to recover from SUD (Baldisseri, 2007; NCSBN, 2011). Healthcare professionals have excellent rates of recovery from SUD. A study related to physician recovery found $71 \%$ of physicians were still licensed and employed at 5-years (DuPont, McLellan, Carr, Gendel, \& Skipper, 2009). Based on the results of this study, physicians may be given a better chance at recovery by less punitive discipline. The physician is also be given the opportunity to continue to practice their chosen profession. If all professionals were disciplined similarly, the profession of nursing may retain more qualified nurses.

Nurses diagnosed with SUD have been found to be high-achieving, excellent practitioners (NCSBN, 2011; Scimeca, 2008). Therefore, with appropriate treatment and recovery, these highly trained and skilled nurses may be retained in a profession experiencing significant shortages (Scimeca, 2008). Nurses are retiring or leaving the profession faster than they can be trained (Goodin, 2003). The profession of nursing has seen significant shortages over the past decade and these shortages are expected to continue in the future (Goodin, 2003). Nurses who are afforded appropriate treatment have excellent recovery rates (Darbro, 2008; NCSBN, 2011). Most nurses with SUD state 
their professional identity is extremely important, wanting to continue to practice their chosen profession (NCSBN, 2011). Appropriate intervention and treatment of nurses with SUD is one way to retain qualified and trained practitioners in the profession of nursing (Darbro, 2008; NCSBN, 2011).

\section{Public Protection}

There is a fine line between allowing professional recovery and allowing dangerous practice placing patients at risk. This secondary data analysis is a retrospective look at actual licensure discipline that is reported to a disciplinary repository. Licensure discipline is dependent on the disciplinary philosophy of the jurisdiction of the licensee, and this final outcome is what is reported to the NPDB. The study sample is also dependent on the reporting accuracy of the regulatory bodies. There are also practice environment factors to consider among the professions that may lend to differences in discipline. For instance nurses are administering medications and have access to medications, leading to diversion. Pharmacists also divert as they fill prescribed medications. Physicians have prescriptive authority, leading to other forms of obtaining substances. These are only a small sample of the differences, but the differences in provision of care among the three professions may influence how they are disciplined. However, in this study each type of discipline is compared directly despite the circumstances leading to the discipline. The differences in practice may be manifested in outcomes like "other" and limitations.

\section{Application to Practice}

There are significant differences between licensure discipline among the four licensure types in the study. Nursing does see more punitive discipline, like revocation 
and fines, and are placed on probation at much higher rates than their medical colleagues. The question here is if the physicians are able to recover at similar rates with less punitive punishment without posing significant harm to patients, why is nursing more punitive?

The nursing practice environment may explain the more punitive penalties imposed on nurses with SUD. There is a body of research identifying nurses have significant horizontal violence and bullying in the profession, which may trickle into the regulatory areas (Becher \& Visovsky, 2012). The regulatory boards disciplining the licensees are comprised of the same profession. Nurses, physicians, and pharmacists are disciplining their own colleagues. The nursing environments have high incidences (60$85 \%$ ) of undermining of professional integrity or reputation, or sabotage, otherwise known as lateral or horizontal violence (Becher \& Visovsky, 2012). This behavior in nursing is not new, and may be embedded in daily practices, causing conscious or unconscious acts of bullying, a potential contributing factor to nurse discipline (Becker \& Visovsky, 2012). Stigma may influence licensure discipline if regulators view SUD as a choice: a nurse should "know better" (Livingston, Miline, Fang, \& Amari, 2011). Further, nursing continues to rank as the most trusted profession (Brenan, 2018). This can place pressure on regulators to maintain the high integrity of the profession and stop those who may taint nursing's hard earned reputation.

The circumstances leading to the disciplinary outcome are different, but this study did not look at this, simply compared outcomes. The violation itself may lead to more punitive discipline, based on how the act is viewed by the regulatory body. If a violation like diversion is viewed as an immoral or significant event to one profession that regulatory body may take harsh action like revocation. Harsh penalties send a message to 
the profession and keep a practitioner deemed dangerous, immoral, or unworthy from practicing the profession.

$\mathrm{RN}$ and LPN discipline have differences, but the discipline is coming from the same regulatory board. West Virginia, Louisiana, and California have separate RN and LPN regulatory boards and all other states have one board of nursing regulating both RNs and LPNs (NCSBN, 2018). These three states are not included in this study. LPNs are fined at the highest rates of all the professions, yet make the least amount of money. Monetary fines may be detrimental to the LPN who is unable or limited to make money practicing their profession. There are differences between RN and LPN disciplinary actions. There is no literature related to SUD on the differences between LPN and RN incidence, use, practice environment, or recovery. The differences in nursing discipline related to SUD found in this study could be explored further in future studies.

\section{The Opioid Crisis}

The United States is in the midst of an opioid epidemic. Information provided by this study tells us healthcare providers have the same propensity to SUD as the general population (Baldisseri, 2007; NCSBN, 2011). If the general population currently is seeing opioid rates rise, so will healthcare providers. To make the issue worse, healthcare providers have direct access to opioids at their places of employment either through prescriptive authority or access (Merlo, Cummings, \& Cottler, 2013; Trinkoff, Zhou, Storr, \& Soeken, 2000). This study provides strong evidence to demonstrate the cases of SUD with healthcare professionals are handled in a multitude of ways. Evidence-based regulation should be explored, as there is a high likelihood of an increase of board cases related to opioid use disorders. Regulators should be prepared for these cases, and also 
evaluate better methods for education of healthcare providers related to SUD and methods of prevention.

\section{Limitations}

Disciplinary action taken on healthcare professionals is a function of state law. The data in this analysis is limited to the accuracy of input and reporting by each licensure jurisdiction. Disciplinary action may vary from state to state and profession to profession depending on the disciplinary philosophy held by each regulatory board.

The sample size was large and representative of the entire population, as well as representative of the predicted rates of SUD among the professions. A large sample provides robust information, as chi-square analysis works very well with larger samples (McHugh, 2013). However, the large sample size may lend to possible type one errors, as the population is large enough to find differences that may not actually exist. While there are statistically significant findings for all types of discipline except for suspension, correlation statistics show low correlations, the strongest correlations were with censure and limitation. This does tell us that there is a stronger correlation with less punitive action and physicians. These correlations were stronger, but still not high; 0.147 and 0.117 respectively.

There are almost four million nurses in the United States, almost four times as many as physicians, and pharmacists number only one third the number of physicians (Bureau of Labor Statistics, 2016; NCSBN, 2015; Young, Chaudhry, Rhyne, \& Dugan, 2013). These numbers contribute to more total numbers of nurses having SUD when compared to physicians and pharmacists. The researcher compared disciplinary action head to head, and chi-square analysis does not require equal samples (McHugh, 2013). 
Another consideration to take into account when interpreting data is the differences in scope of practice. Nurses, both LPN and RN and pharmacists are going to have more cases of diversion than physicians would have based on their job duties. Whereas physicians may have more cases of prescription fraud in obtaining controlled substances.

Length of terms of discipline was not taken into account in this study. The length of probation and suspension and amount of administrative fines will vary from case to case. Each type of disciplinary action was compared head to head. The length of terms may be explored for probation to provide more information on punitive punishment and regulatory consistency.

\section{Conclusion}

With SUD rates at an all-time high in the United States, the healthcare provider is no exception and regulators will continue to see problems with impaired or addicted professionals (National Institute on Drug Abuse [NIDA], 2018). Looking further into how cases of addiction are handled in the midst of a constantly changing healthcare delivery system is prudent. The disciplinary standards and philosophies held by regulators for years should be evaluated in the midst of the changing practice environment. Regulators must work to find the appropriate balance between public protection and patient safety while maintaining our skilled workforce. This secondary data analysis informs us there are inconsistent licensure sanctions across the professions. Inconsistency leads to misconceptions and confusion as to how this disease is managed in the regulatory realm. There is more research to be done to support these claims. This 
research is the beginning of further studies to provide evidence to support regulatory practices. 
Appendix A

\section{National Provider Data Bank Public Use File (2018)}

\begin{tabular}{|c|c|c|c|c|c|}
\hline Variable & Type & $\begin{array}{cc}\text { Variable Label } \\
\end{array}$ & Length & Start & End \\
\hline seqno & Numeric & Sequence Number -- Unique to Each Record & 8 & 1 & 8 \\
\hline rectype & String & Record Type & 1 & 9 & 9 \\
\hline reptype & Numeric & Report Type & 4 & 10 & 13 \\
\hline origyear & Numeric & Year original report processed & 4 & 14 & 17 \\
\hline workstat & String & Practitioners Work State & 2 & 18 & 19 \\
\hline workctry & String & Practitioners Work Country & 10 & 20 & 29 \\
\hline homestat & String & Practitioners Home State & 2 & 30 & 31 \\
\hline homectry & String & Practitioners Home Country & 10 & 32 & 41 \\
\hline licnstat & String & Practitioners State of License (First Listed) & 2 & 42 & 43 \\
\hline licnfeld & Numeric & Practitioners Field of License & 4 & 44 & 47 \\
\hline practage & Numeric & Age Group of Practitioner & 2 & 48 & 49 \\
\hline grad & Numeric & Graduation year group & 4 & 50 & 53 \\
\hline algnnatr & Numeric & Malpractice Allegation Group & 8 & 54 & 61 \\
\hline alegatn1 & Numeric & Specific Malpractice Allegation 1 & 8 & 62 & 69 \\
\hline alegatn2 & Numeric & Specific Malpractice Allegation 2 & 8 & 70 & 77 \\
\hline outcome & Numeric & $\begin{array}{l}\text { Severity of Alleged Malpractice Injury [available for use } \\
1 / 31 / 2004 \text { ] }\end{array}$ & 8 & 78 & 85 \\
\hline malyear1 & Numeric & Year of Act or Omission 1 & 4 & 86 & 89 \\
\hline malyear2 & Numeric & Year of Act or Omission 2 & 4 & 90 & 93 \\
\hline payment & Dollar & Payment Amount (this payment only) & 12 & 94 & 105 \\
\hline totalpmt & Dollar & $\begin{array}{l}\text { Total Payment by this Payer for This Practitioner } \\
\text { [available for use } 1 / 31 / 2004 \text { ] }\end{array}$ & 12 & 106 & 117 \\
\hline paynumbr & String & Single of Multiple Payment & 1 & 118 & 118 \\
\hline numbprsn & Numeric & Number of Practitioners Payment For & 3 & 119 & 121 \\
\hline paytype & String & Payment A Result of ... & 1 & 122 & 122 \\
\hline pyrrltns & String & $\begin{array}{l}\text { Relationship of Paying Entity to the Practitioner } \\
\text { [available for use } 1 / 31 / 2004 \text { ] }\end{array}$ & 1 & 123 & 123 \\
\hline ptage & Numeric & Age Group of Patient [available for use $1 / 31 / 2004$ ] & 2 & 124 & 125 \\
\hline ptgender & String & Gender of Patient [available for use $1 / 31 / 2004$ ] & 1 & 126 & 126 \\
\hline pttype & String & Patient Type (Inpatient, Outpatient) & 1 & 127 & 127 \\
\hline aayear & Numeric & Year of Adverse Action & 4 & 128 & 131 \\
\hline aaclass1 & Numeric & $\begin{array}{l}\text { Adverse Action Classification1 [available for use } \\
\text { 11/22/1999/old records converted] }\end{array}$ & 4 & 132 & 135 \\
\hline aaclass2 & Numeric & $\begin{array}{l}\text { Adverse Action Classification2 [available for use } \\
11 / 22 / 1999 \text { ] }\end{array}$ & 4 & 136 & 139 \\
\hline
\end{tabular}




\begin{tabular}{|c|c|c|c|c|c|}
\hline Variable & Type & $\begin{array}{l}\text { Variable Label } \\
\end{array}$ & Length & Start & End \\
\hline aaclass3 & Numeric & $\begin{array}{l}\text { Adverse Action Classification3 [available for use } \\
11 / 22 / 1999 \text { ] }\end{array}$ & 4 & 140 & 143 \\
\hline aaclass 4 & Numeric & $\begin{array}{l}\text { Adverse Action Classification4 [available for use } \\
11 / 22 / 1999 \text { ] }\end{array}$ & 4 & 144 & 147 \\
\hline aaclass 5 & Numeric & $\begin{array}{l}\text { Adverse Action Classification5 [available for use } \\
11 / 22 / 1999 \text { ] }\end{array}$ & 4 & 148 & 151 \\
\hline basiscd1 & String & Basis for Action [available for use 11/22/1999] & 2 & 152 & 153 \\
\hline basiscd 2 & String & Basis for Action2 [available for use $11 / 22 / 1999$ ] & 2 & 154 & 155 \\
\hline basiscd3 & String & Basis for Action3 [available for use 11/22/1999] & 2 & 156 & 157 \\
\hline basiscd4 & String & Basis for Action4 [available for use $11 / 22 / 1999$ ] & 2 & 158 & 159 \\
\hline basiscd5 & String & Basis for Action5 [available for use 9/9/2002] & 2 & 160 & 161 \\
\hline aalentyp & String & Adverse Action Length Type & 1 & 162 & 162 \\
\hline aalength & Numeric & Length of Adverse Action Penalty, in Years & 8 & 163 & 170 \\
\hline aaefyear & Numeric & Effective Year of Adverse Action & 4 & 171 & 174 \\
\hline aasigyr & Numeric & Year of AA Report Signature & 4 & 175 & 178 \\
\hline type & Numeric & Entity Type (assigned) & 3 & 179 & 181 \\
\hline practnum & Numeric & Practitioner Number Unique to This File & 8 & 182 & 189 \\
\hline accrrpts & Numeric & Subjects Number of Accreditation Reports & 4 & 190 & 193 \\
\hline npmalrpt & Numeric & $\begin{array}{l}\text { Practitioners Number of Malpractice Payment Reports } \\
\text { submitted under Title IV. }\end{array}$ & 4 & 194 & 197 \\
\hline nplicrpt & Numeric & $\begin{array}{l}\text { Practitioners Number of Licensure Reports submitted } \\
\text { under Title IV and/or Section } 1921\end{array}$ & 4 & 198 & 201 \\
\hline npclprpt & Numeric & $\begin{array}{l}\text { Practitioners Number of Clinical Privileges Reports } \\
\text { submitted under Title IV }\end{array}$ & 4 & 202 & 205 \\
\hline nppsmrpt & Numeric & $\begin{array}{l}\text { Practitioners Number of Prof. Soc. Membership Reports } \\
\text { submitted under Title IV }\end{array}$ & 4 & 206 & 209 \\
\hline npdearpt & Numeric & $\begin{array}{l}\text { Practitioners Number of DEA Reports submitted under } \\
\text { Title IV }\end{array}$ & 4 & 210 & 213 \\
\hline npexcrpt & Numeric & $\begin{array}{l}\text { Practitioners Number of Exclusion Reports submitted } \\
\text { under Title IV and/or Section } 1921\end{array}$ & 4 & 214 & 217 \\
\hline npgarpt & Numeric & $\begin{array}{l}\text { Practitioners Number of Government Administrative } \\
\text { Reports submitted under Section } 1921\end{array}$ & 4 & 218 & 221 \\
\hline npctmrpt & Numeric & $\begin{array}{l}\text { Practitioners Number of Contract Termination Reports } \\
\text { submitted under Section } 1921\end{array}$ & 4 & 222 & 225 \\
\hline fundpymt & Numeric & State Patient Compensation, etc., Fund Payment & 1 & 226 & 226 \\
\hline
\end{tabular}


Appendix B

\section{NLCV)}

\section{Nurse Licensure Compact (NLC) States}

Jpdated 3/9/2015

\begin{tabular}{|c|c|}
\hline COMPACT STATE & IMPLEMENTATION DATE \\
\hline Arizona & $7 / 1 / 2002$ \\
\hline Arkansas & $7 / 1 / 2000$ \\
\hline Colorado & $10 / 1 / 2007$ \\
\hline Delaware & $7 / 1 / 2000$ \\
\hline Idaho & $7 / 1 / 2000$ \\
\hline lowa & $7 / 1 / 2000$ \\
\hline Kentucky & $6 / 1 / 2007$ \\
\hline Maine & $7 / 1 / 2001$ \\
\hline Maryland & $7 / 1 / 1999$ \\
\hline Mississippi & $7 / 1 / 2001$ \\
\hline Missouri & $6 / 1 / 2010$ \\
\hline Montana & $10 / 1 / 2015$ \\
\hline Nebraska & $1 / 1 / 2001$ \\
\hline New Hampshire & $1 / 1 / 2006$ \\
\hline New Mexico & $1 / 1 / 2004$ \\
\hline North Carolina & $7 / 1 / 2000$ \\
\hline North Dakota & $1 / 1 / 2004$ \\
\hline Rhode Island & $7 / 1 / 2008$ \\
\hline South Carolina & $2 / 1 / 2006$ \\
\hline South Dakota & $1 / 1 / 2001$ \\
\hline Tennessee & $7 / 1 / 2003$ \\
\hline Texas & $1 / 1 / 2000$ \\
\hline Utah & $1 / 1 / 2000$ \\
\hline Virginia & $1 / 1 / 2005$ \\
\hline Wisconsin & $1 / 1 / 2000$ \\
\hline
\end{tabular}


Appendix C

\section{ARTICLE VI}

\section{From the Nurse Licensure Compact Statutes}

Coordinated Licensure Information System and Exchange of Information

a. All party states shall participate in a coordinated licensure information system of all licensed registered nurses and licensed practical/vocational nurses. This system will include information on the licensure and disciplinary history of each nurse, as submitted by party states, to assist in the coordination of nurse licensure and enforcement efforts.

b. The Interstate Commission of Nurse Licensure Compact Administrators, in consultation with the administrator of the coordinated licensure information system, shall formulate necessary and proper procedures for the identification, collection, and exchange of information under this Compact.

c. All licensing boards shall promptly report to the coordinated licensure information system any adverse action, any current significant investigative information, denials of applications (with the reasons for such denials), and

nurse participation in alternative programs known to the licensing board regardless of whether such participation is deemed nonpublic or confidential under state law.

d. Current significant investigative information and participation in nonpublic or confidential alternative programs shall be transmitted through the coordinated licensure information system only to party state licensing boards.

e. Notwithstanding any other provision of law, all party state licensing boards contributing information to the coordinated licensure information system may designate information that may not be shared with nonparty states or disclosed to other entities or individuals without the express permission of the contributing state.

f. Any personally identifiable information obtained from the coordinated licensure information system by a party state licensing board shall not be shared with nonparty states or disclosed to other entities or individuals except to the extent permitted by the laws of the party state contributing the information.

g. Any information contributed to the coordinated licensure information system that is subsequently required to be expunged by the laws of the party state contributing that information shall also be expunged from the coordinated licensure information system.

h. The Compact administrator of each party state shall furnish a uniform data set to the Compact administrator of each other party state, which shall include, at a minimum:

1. Identifying information;

2. Licensure data;

3. Information related to alternative program participation; and

4. Other information that may facilitate the administration of this Compact, as determined

by rules of the Interstate Commission of Nurse Licensure Compact Administrators.

i. The Compact administrator of a party state shall provide all investigative documents and information requested by another party state. 
Appendix D

Data Analysis Results

Does the type of disciplinary action taken for violations related to SUD differ significantly among licensure types (physicians, nurses, or pharmacists)?

\begin{tabular}{|c|c|c|c|c|c|c|}
\hline & MD & RX & RN & LPN & Sig & Total \\
\hline \multicolumn{7}{|l|}{ Discipline } \\
\hline Revocation & $\begin{array}{l}85 / 182.2 \\
5.3 \% \text { of } M D \\
\text { discipline }\end{array}$ & $\begin{array}{l}9 / 4.7 \\
22 \% \text { of } \mathrm{RX} \\
\text { discipline }\end{array}$ & $\begin{array}{l}1095 / 1219.9 \\
10.2 \% \text { of } \mathrm{RN} \\
\text { total discipline }\end{array}$ & $\begin{array}{l}\mathbf{7 9 7 / 5 7 9 . 3} \\
15.6 \% \text { of LPN } \\
\text { total discipline }\end{array}$ & $\begin{array}{l}\text { YES } \\
\mathrm{p}=.000\end{array}$ & $\begin{array}{l}11.4 \% \text { of total } \\
\text { discipline }\end{array}$ \\
\hline Probation & $\begin{array}{l}197 / 393.2 \\
12.3 \% \text { of } \\
\mathrm{MD} \\
\text { discipline } \\
\end{array}$ & $\begin{array}{l}14 / 10.1 \\
34.1 \% \text { of } \mathrm{R} X \\
\text { discipline }\end{array}$ & $\begin{array}{l}\mathbf{2 8 5 9 / 2 6 3 3 . 3} \\
26.6 \% \text { of } \mathrm{RN} \\
\text { discipline }\end{array}$ & $\begin{array}{l}1217 / 1250.5 \\
23.9 \% \text { of LPN } \\
\text { discipline }\end{array}$ & $\begin{array}{l}\text { YES } \\
p=0.000\end{array}$ & $\begin{array}{l}24.5 \% \text { of total } \\
\text { discipline }\end{array}$ \\
\hline Suspension & $\begin{array}{l}451 / 458 \\
28.1 \% \text { of } \\
\text { MD } \\
\text { discipline }\end{array}$ & $\begin{array}{l}7 / 11.7 \\
17.1 \% \text { of } \mathrm{RX} \\
\text { discipline }\end{array}$ & $\begin{array}{l}3051 / 3072.5 \\
28.4 \% \text { of } \mathrm{RN} \\
\text { discipline }\end{array}$ & $\begin{array}{l}\mathbf{1 4 9 3 / 1 4 5 9} \\
29.3 \% \text { of LPN } \\
\text { discipline }\end{array}$ & $\begin{array}{l}\text { NO } \\
p=.243\end{array}$ & $\begin{array}{l}28.6 \% \text { of total } \\
\text { discipline }\end{array}$ \\
\hline Censure & $\begin{array}{l}298 / 109.3 \\
18.5 \% \text { of } \\
\text { MD } \\
\text { discipline }\end{array}$ & $\begin{array}{l}0 / 2.8 \\
0 \% \text { of } \mathrm{RX} \\
\text { discipline }\end{array}$ & $\begin{array}{l}620 / 732.2 \\
5.8 \% \text { of } \mathrm{RN} \\
\text { discipline }\end{array}$ & $\begin{array}{l}276 / 347.7 \\
5.4 \% \text { of Nurse } \\
\text { discipline }\end{array}$ & $\begin{array}{l}\text { YES } \\
\mathrm{p}=.000\end{array}$ & $\begin{array}{l}11.4 \% \text { of total } \\
\text { SUD discipline }\end{array}$ \\
\hline $\begin{array}{l}\text { Voluntary } \\
\text { Surrender }\end{array}$ & $\begin{array}{l}205 / 281.4 \\
12.8 \% \text { of } \\
\text { MD } \\
\text { discipline }\end{array}$ & $\begin{array}{l}9 / 7.2 \\
22 \% \text { of } \mathrm{RX} \\
\text { discipline }\end{array}$ & $\begin{array}{l}\mathbf{2 0 0 2 / 1 8 8 4 . 5} \\
18.6 \% \text { of } \mathrm{R} N \\
\text { discipline }\end{array}$ & $\begin{array}{l}852 / 894 \\
16.7 \% \text { of LPN } \\
\text { discipline }\end{array}$ & $\begin{array}{l}\text { YES } \\
p=0.000\end{array}$ & $17.5 \%$ of total \\
\hline Limitation & $\begin{array}{l}246 / 105.9 \\
15.3 \% \text { of } \\
\text { MD } \\
\text { discipline }\end{array}$ & $\begin{array}{l}1 / 2.7 \\
2.4 \% \text { of } \mathrm{RX} \\
\text { discipline }\end{array}$ & $\begin{array}{l}679 / 709.5 \\
6.3 \% \text { of } \mathrm{RN} \\
\text { discipline }\end{array}$ & $\begin{array}{l}229 / 336 \\
4.5 \% \text { of LPN } \\
\text { discipline }\end{array}$ & $\begin{array}{l}\text { YES } \\
p=0.000\end{array}$ & $6.6 \%$ of total \\
\hline $\begin{array}{l}\text { Negative } \\
\text { action }\end{array}$ & $\begin{array}{l}\mathbf{1 6 / 4 . 9} \\
1 \% \text { of } \mathrm{MD} \\
\text { discipline }\end{array}$ & $\begin{array}{l}0 / 0.1 \\
0 \% \text { of } \mathrm{RX} \\
\text { discipline }\end{array}$ & $\begin{array}{l}26 / 32.6 \\
0.2 \% \text { of all } \\
\text { RN discipline }\end{array}$ & $\begin{array}{l}11 / 15.5 \\
0.2 \% \text { of all LPN } \\
\text { discipline }\end{array}$ & $\begin{array}{l}\text { YES } \\
p=0.000\end{array}$ & $0.3 \%$ of total \\
\hline $\begin{array}{l}\text { Monetary } \\
\text { Fines }\end{array}$ & $\begin{array}{l}85 / 176.6 \\
5.3 \% \text { of } \mathrm{MD} \\
\text { discipline } \\
\end{array}$ & $\begin{array}{l}3 / 4.5 \\
7.3 \% \text { of } \mathrm{RX} \\
\text { discipline }\end{array}$ & $\begin{array}{l}1075 / 1182.4 \\
10 \% \text { of } \mathrm{RN} \\
\text { discipline }\end{array}$ & $\begin{array}{l}\mathbf{7 6 2 / 5 6 1 . 5} \\
14.9 \% \text { of LPN } \\
\text { discipline } \\
\end{array}$ & $\begin{array}{l}\text { YES } \\
p=0.000\end{array}$ & $11 \%$ of total \\
\hline Other & $\begin{array}{l}278 / 249 \\
1.6 \% \text { of } \mathrm{MD} \\
\text { discipline }\end{array}$ & $\begin{array}{l}2 / 6.4 \\
4.9 \% \text { of } \mathrm{RX} \\
\text { discipline }\end{array}$ & $\begin{array}{l}1607 / 1672 \\
15 \% \text { of } \mathrm{RN} \\
\text { discipline }\end{array}$ & $\begin{array}{l}\mathbf{8 3 5 / 7 9 4} \\
16.5 \% \text { or LPN } \\
\text { discipline }\end{array}$ & $\begin{array}{l}\text { YES } \\
p=0.005\end{array}$ & $15.6 \%$ of total \\
\hline
\end{tabular}

** Total percentages equal greater than $100 \%$ because of the case-by-case nature of licensure discipline. Multiple sanctions may be taken on one licensee by a licensing jurisdiction based on singular or multiple SUD disciplinary grounds. 


\section{References}

American Medical Association Council on Mental Health (1973). The sick physician: Impairment by psychiatric disorders, including alcoholism and drug dependence. JAMA, 223, 684-687.

American Medical Association [AMA], (2016). AMA code of medical ethics. Retrieved from: https://www.ama-assn.org/sites/ama-assn.org/files/corp/mediabrowser/principles-of-medical-ethics.pdf

American Nurses Association (1984a). Addictions and psychological dysfunction in nursing. Kansas City, MO: Author.

American Nurses Association [ANA], (1984b). The profession's response to the problem of addictions and psychiatric disorders in nursing. ANA House of Delegates Resolution.

American Nurses Association [ANA], (2010). Nursing's social policy statement. $\left(3^{\text {rd }}\right.$ Ed.). Silver Spring, MD: American Nurses Association.

American Nurses Association [ANA], 2015. Code of ethics for nurses with interpretive statements. (2 ${ }^{\text {nd }}$ Ed.). Silver Spring, MD: American Nurses Association.

American Pharmacy Association [APhA], (1994). Code of ethics for pharmacists.

Retrieved from: https://www.pharmacist.com/code-ethics

American Psychiatric Association [APA] (1994). Diagnostic and statistical manual of mental disorders. (4 ${ }^{\text {th }}$ ed.). Washington, D.C.: American Psychiatric Association. Angres, D.H., Talbott, G.D., \& Bettinardi-Angres, K. (2012) Healing the healer. Scott's Valley, CA: Createspace. 
Baldisseri, M. R. (2007). Impaired healthcare professional. Critical Care Medicine, 35(Suppl), S106-S116. https://doi.org/10.1097/01.CCM.0000252918.87746.96

Baldwin, J.A., Bartek, J.K., Scott, D.M., Davis-Hall, R.E, \& DeSimone II, E.M., (2009). Survey of alcohol and other drug use attitudes and behaviors in nursing students. Substance Abuse, 30 (3), 230-238. doi: 10.1080/0889707090304096.4

Baldwin, J.N., Davis-Hall, E.R., DeSimone II, E.M., Scott, D.M., Agrawal, S., \& Reardon, T.P. (2008). Survey of attitudes and behaviors toward alcohol and other drug use in allied health and physician assistant students. Journal of Allied Health $37(3), 158-61$.

Baldwin, J. N., Scott, D. M., DeSimone II, E. M., Forrester, J. H., \& Fankhauser, M. P. (2011). Substance use attitudes and behaviors at three pharmacy colleges. Substance Abuse, 32(1), 27-35. https://doi.org/10.1080/08897077.2011.540470

Becher, C. \& Visovsky, C. (2012). Horizontal violence in nursing. MedSurg Nursing 21 (4), 210-232.

Beckstead, J. W. (2005). Reporting peer wrongdoing in the healthcare profession: The role of incompetence and substance abuse information. International Journal of Nursing Studies, 42(3), 325-331. https://doi.org/10.1016/j.ijnurstu.2004.07.003

Berge, K.H., Dillon, K.R., Sikkink, K.M., Taylor, T.K., \& Lanier, W.L. (2012). Diversion of drugs within healthcare facilities, a multiple-victim crime: Patterns of diversion, scope, consequences, detection, and prevention. Mayo Clinic Proceedings, 87, (7), 674-682.

Bettinardi-Angres, K \& Angres, D.H. (2010). Understanding the disease of addiction. Journal of Nursing Regulation, 1 (2), 31-37. 
Bettinardi-Angres, K., \& Bologeorges, S. (2011). Addressing chemically dependent colleagues. Journal of Nursing Regulation, 2(2), 10-17.

Bos, A.E., Pryor, J.B., Reeder, G.D., \& Stutterheim, S.E. (2013). Stigma: Advances in theory and research. Basic and Applied Social Psychology (35),1-9.. doi: $10.1080 / 01972533.2012 .746147$

Boulton, M. A., \& Nosek, L. J. (2014). How do nursing students perceive substance abusing nurses? Archives of Psychiatric Nursing, 28(1), 29-34. https://doi.org/10.1016/j.apnu.2013.10.005

Brenan, M. (2018) Nurses again outpace other professions for honesty, ethics. Gallup News. Retrieved from: https://news.gallup.com/poll/245597/nurses-again-outpaceprofessions-honesty-ethics.aspx

Bryson, E.O. (2012). Addicted Healers: 5 Key signs your healthcare professional may be drug impaired. Far Hills, NJ: New Horizon Press.

Bryson, E.O. \& Silverstein, J.H. (2008). Addiction and substance abuse in anesthesiology. Anesthesiology, 109 (5), 905-917.

Bureau of Labor Statistics, (2016). Workforce data. Retrieved from: https://www.bls.gov/oes/current/oes291141.htm

Darbro, N. (2005). Alternative diversion programs for nurses with impaired practice: Completers and non-completers: Journal of Addictions Nursing, 16(4), 169-185. doi:10.1080/10884600500328155

DesRoches, C. M., Rao, S. R., Fromson, J. A., Birnbaum, R. J., Iezzoni, L., Vogeli, C., \& Campbell, E. G. (2010). Physicians' perceptions, preparedness for reporting, and 
experiences related to impaired and incompetent colleagues. JAMA: Journal of the American Medical Assoication, 304(2), 187-193.

Dittman, P. W. (2008). Male nurses and chemical dependency: Masterminding the nursing environment. Nursing Administration Quarterly, 32(4), 324-330.

Doweiko, H.E. (2015). Concepts of chemical dependency $\left(9^{\text {th }}\right.$ Ed.). Boston, MA: Cengage.

DuPont, R.L. McLellan, T.A., Carr, G., Gendel, M., \& Skipper, G.E. (2009) How are addicted physicians treated? A national survey of physician health programs. Journal of Substance Abuse Treatment 37 (1), 1-7.

Garland, D., \& Sparks, R. (Eds.). (2000). Criminology and social theory. New York, NY: Oxford University Press.

Goffman, I (1963). Stigma: Notes on the management of spoiled identity. New York, NY: Simon \& Schuster.

Goodin, H.J. (2003). The nursing shortage in the United States of America: An integrative review of the literature. Journal of Advanced Nursing 43(4), 335-350.

Grower, S. M., \& Floyd, M. R. (1998). Nurses' attitudes toward impaired practice and knowledge of peer assistance programs. Journal of Addictions Nursing, 10(2), 7076.

Haack, M., \& Yocum, C. (2002). State policies and nurses with substance use disorders. Journal of Nursing Scholarship, 34, 89-94.

Health Resources \& Services Administration [HRSA) United States Department of Health and Human Services, (2016). NPDB e-Guidebook. Retrieved from: https://www.npdb.hrsa.gov/resources/aboutGuidebooks.jsp 
Heise, B. (2003). The historical context of addiction in the nursing profession: 18501982. Journal of Addictions Nursing, 14 (3),117-124.

Doi:10.1080/10884600390245695

Kenna, G. A., \& Lewis, D.C. (2008). Risk factors for alcohol and other drug use by healthcare professionals. Substance Abuse Treatment, Prevention, and Policy 3,(3). Doi: 10.1186/1747-597X-3.

Kenna, G.A., \& Wood, M.D. (2005). Family history of alcohol and drug use in healthcare professionals. Journal of Substance Use 10 (4), 225-238.

Kunyk, D. (2015). Substance use disorders among registered nurses: prevalence, risks and perceptions in a disciplinary jurisdiction. Journal of Nursing Management, 23(1), 54-64.

LaGodna, G.E., \& Hendrix, M.J. (1989). Impaired nurses: A cost analysis. Journal of Nursing Administration 19, (9), 13-18.

Lillibridge, J., Cox, M., \& Cross, W. (2002). Uncovering the secret: Giving voice to the experiences of nurses who misuse substances. Journal of Advanced Nursing, 39(3), 219-229. https://doi.org/10.1046/j.1365-2648.2002.02268.x

Link, B.G., \& Phelan, J.C. (2001). Conceptualizing stigma. Annual Review of Sociology, 27, 363-385. Doi.org/10.1146/annurev.soc.27.1.363.

Lipari, R.N., \& Van Horn, S.L. (2017). Trends in substance use disorders among adults aged 18 or older. The CBHSQ Report, National Survey on Drug Use and Health, short report Substance Abuse and Mental Health Services Administration. Retrieved from: 
https://www.samhsa.gov/data/sites/default/files/report_2790/ShortReport2790.html.

Livingston, J.D., Miline, T., Fang, M.L., \& Amari, E. (2011). The effectiveness of interventions for reducing stigma related to substance use disorders: A systematic review. Addiction 107, 39-50. doi: 10.1111/j.1360-0443.2011.03601.x

Major, B., \& O’Brien, L.T. (2005). The social psychology of stigma. Annual Review of Psychology 56, 393-421. doi: 10.1146/annurev.psych.56.091.103.0701.37

Martinez, R.J. \& Murphy-Parker, D. (2003). Examining the relationship of addiction education and beliefs of nursing students toward persons with alcohol problems. Archives of Psychiatric Nursing 17 (4), 156-164. doi: 10.1016/SI8839417(03)00086-4

Mason, D.J., Gardner, D.B., Outlaw, F.H., \& O’Grady, E.T. (Eds.) (2016). Policy and politics in nursing and health care $\left(7^{\text {th }}\right.$ ed.). St. Louis, MO: Elsevier.

McHugh, M.L. (2013). The chi-square test of independence. Biochemia Medica 23 (2), 143-149. https://doi.org/10.11613/BM.2013.018.

McLellan, A.T., Skipper, G.S., Campbell, M., \& DuPont, R.L (2008). Five year outcomes in a cohort study of physicians treated for substance use disorders in the United States. BMJ: British Medical Journal. 337, (7679), 1154-1156.

Merlo, L. J., Cummings, S. M., \& Cottler, L. B. (2012). Recovering substance-impaired pharmacists' views regarding occupational risks for addiction. Journal of the American Pharmacists Association, 52(4), 480-491. doi.org/10.1331/JAPhA.2012.10214 
Merlo. L.J., \& Gold, M.S. (2008). Prescription opioid abuse and dependence among physicians: Hypotheses and treatment. Harvard Review of Psychiatry 16, (3), 181194. Doi: $10.1080 / 10673220802160316$

Merlo, L.J., Singhakand, S., Cummings, S.M., \& Cottler, L.B. (2013). Patterns of substance use initation among healthcare professionals in rovery: Substance use initiation. Journal of Addiction Medicine 7, (3), 349-353. Doi:

10.1097/ADM.0b13e31829da074

Merlo, L. J., Trejo-Lopez, J., Conwell, T., \& Rivenbark, J. (2013). Patterns of substance use initiation among healthcare professionals in recovery: Substance Use Initiation. The American Journal on Addictions, 22(6), 605-612.

https://doi.org/10.1111/j.1521-0391.2013.12017.x

Monroe, T. \& Kenaga, H. (2011). Don't ask don't tell: Substance abuse and addiction among nurses. Journal of Clinical Nursing 20 (3-4), 504-509. doi:10.1111/j.13652702.2010.03518.x

Monroe, T.B., Kenaga, H., Dietrich, M.S., Carter, M.A., Cowan, R.L., (2013). The prevalence of employed nurses identified or enrolled in substance use monitoring programs. Nursing Research 62 (1), 10-15. doi:10.1097/NNR.0b013e31826ba3ca

Monroe, T., Pearson, F., \& Kenaga, H. (2008). Procedures for handling cases of substance abuse among nurses: A comparison of disciplinary and alternative programs: Journal of Addictions Nursing, 19(3), 156-161.

https://doi.org/10.1080/10884600802306024

National Council of State Boards of Nursing (2011). Substance abuse disorder in nursing. Chicago, IL: National Council of State Boards of Nursing. 
National Council of State Boards of Nursing (2015). Nurse License Compact. Retrieved from: https://www.ncsbn.org/NLC_Final_050415.pdf

National Council of State Boards of Nursing, (2017). NURSYS. Retrieved from: https://www.ncsbn.org/nursys.htm

National Council of State Boards of Nursing (2018a). A profile of nursing licensure in the U.S. The National Nursing Database. Retrieved from: https://www.ncsbn.org/national-nursing-database.htm

National Council of State Boards of Nursing. (2018b). Discipline and board action. Retrieved from: https://www.ncsbn.org/673.htm\#12253

National Institute on Alcohol Abuse and Alcoholism [NIAAA] (2008) Alcohol use disorder. Retrieved from: https://www.niaaa.nih.gov/

National Institute on Drug Abuse [NIDA] (2018). Trends and statistics. Retrieved from: https://www.drugabuse.gov/related-topics/trends-statistics

Neville, K. \& Roan, N. (2014). Challenges in nursing practice: Nurses'perceptions in caring for hospitalized medical-surgical patients with substance abuse/dependence. JONA: The Journal of Nursing Administration 44 (6), 339-346. doi: 10.1097/NNA.0000000000000079

Polit, D.F., \& Beck, C.T. (2017). Nursing research: Generating and assessing evidence for nursing practice $\left(10^{\text {th }}\right.$ ed.). Philadelphia, PA: Wolters Kluwer.

Pryor, J.B., Reeder, G.D., \& Monroe, A.E. (2012) The infection of bad company: Stigma by association. Journal of Personality and Social Psychology 102 (2), 224-241.

Quinlan, D. (2003). Impaired nursing practice: A national perspective on peer assistance in the U.S. Journal of Addictions Nursing, 14 (3), 149-155. 
Scambler, G. (2009). Health related stigma. Sociology of Health \& Illness 31 (3), 441455. Doi: 10.1111/j.1467-9566.2009.01161.x.

Schaefer, M. K., \& Perz, J. F. (2014). Outbreaks of infections associated with drug diversion by US health care personnel. Mayo Clinic Proceedings, 89(7), 878-887. https://doi.org/10.1016/j.mayocp.2014.04.007

Scimeca, P.D. (2008). Unbecoming a nurse: Bypassing the hidden chemical dependency trap. Staten Island, NY: Sea Meca.

Shaw, M. F., McGovern, M. P., Angres, D. H., \& Rawal, P. (2004). Physicians and nurses with substance use disorders. Journal of Advanced Nursing, 47(5), 561-571.

Substance Abuse and Mental Health Administration [SAMSHA], (2014). Results from the 2016 national survey on drug use and health. Retrieved from: https://www.samhsa.gov/data/sites/default/files/NSDUH-DetTabs-2016/NSDUHDetTabs-2016.pdf

Trivedi, A.N., Nsa, W., Hausmann, L.R., Lee, J.S., Ma, A., Bratzler, D.W.,.....Fine, M.J. (2014). Quality and equity of care in U.S. hospitals. The New England Journal of Medicine 371(24), 2298-2308.

Trinkoff, A. M., \& Storr, C. L. (1998). Substance use among nurses: Differences between specialties. Journal of Addictions Nursing, 10(2), 77-84.

Trinkoff, A. M., Zhou, Q.,, Storr, C.L., \& Soeken, K.L. (2000). Workplace access, negative proscriptions, job strain, and substance use in registered nurses. Nursing Research, 49 (2), 83-90.

United States Department of Health and Human Services [DHHS], Health Resources and Services Administration [HRSA] (2018). National Provider Data Bank [NPDB] 
guidebook. Rockville, MD: United States Department of Health and Human Services.

Vito, G.F., \& Maahs, J.R. (2017). Criminology: Theory, research, and policy. ( $4^{\text {th }}$ ed.). Burlington, MA: Jones \& Bartlett Learning.

Warr, M., Meier, R.F., \& Erickson, M.L. (1983). Norms, theories of punishment, and publicly preferred penalties for crimes. The Sociological Quarterly,24,75-91.

West, M.M. (2003). A kaleidoscopic review of literature about substance abuse impairment in nursing: Progress toward identification of early risk indicators? Journal of Addictions Nursing, 14 (3), 139-144. DOI: 10.1080/10884600390245721

Young, A., Chaudhry, H.J., Pei, X., Arnhart, K., Dugan, M., \& Snyder, G.B. (2017). A census of actively licensed physicians in the United States, 2016. Journal of Medical Regulation 103 (2), 7-21. 


\section{VITA}

Nancy (Niki) Eisenmann was born on June 1, 1979, in Laramie, Wyoming. She was educated in local public schools and graduated from Wheatland High School (Wyoming) in 1998. She attended the University of Nebraska at Kearney and went on to attend nursing school at the University of Nebraska Medical Center, graduating with a Bachelor of Science in Nursing degree in 2002. She went on to work as a bedside nurse and became a certified orthopaedic nurse in 2007.

Niki attended Nebraska Wesleyan University, graduating with a Master of Science in Nursing with an emphasis in nursing education in 2008. She took a position as the practice consultant with the Nebraska Board of Nursing. In 2016, Niki took a position with Bryan College of Health Sciences as an Assistant Professor of Nursing to pursue her passion of nursing education. Ms. Eisenmann went on to pursue a Doctor of Philosophy degree at the University of Missouri Kansas City. She was honored as a Jonas Nurse Leader scholar during her educational tenure. Upon completion of her degree plans to continue teaching undergraduate and graduate nursing students and pursue research interests.

Niki is a member of the American Nurses Association and is the chair of the Legislative Action and Representation committee, a part of the Board of Directors of the Nebraska Nurses Association. She also is a member of Sigma Theta Tau and serves as the $\mathrm{Nu}$ Rho Chapter research chair. She also belongs to Midwest Nursing Research Society and has given numerous presentations on the subject of substance use disorders in the nursing profession. 